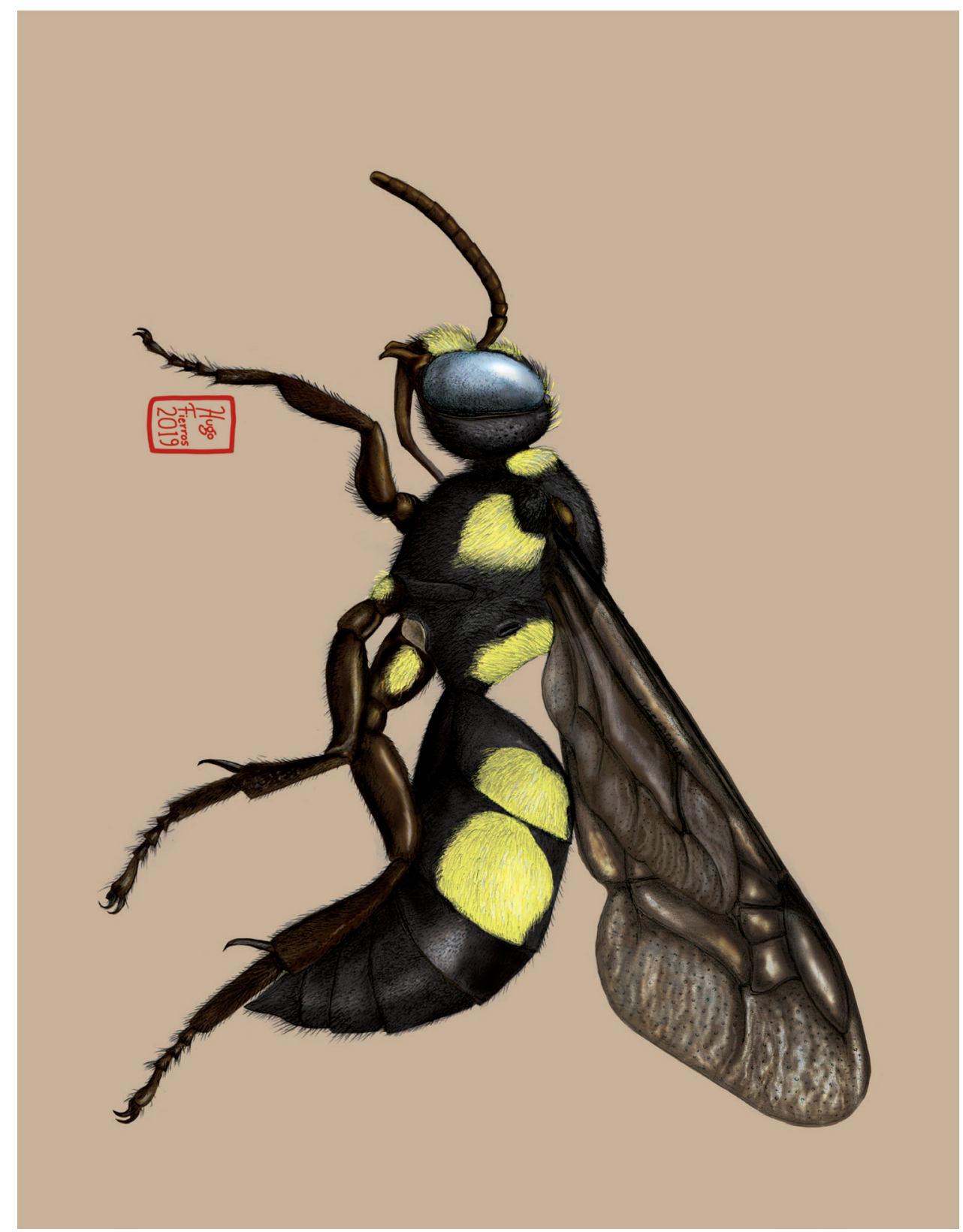

Dugesiana, Año 27, No. 1, enero 2020-junio 2020 (primer semestre de 2020), es una publicación semestral, editada por la Universidad de Guadalajara, a través del Centro de Estudios en Zoología, por el Centro Universitario de Ciencias Biológicas y Agropecuarias. Camino Ramón Padilla Sánchez \# 2100, Nextipac, Zapopan, Jalisco, Tel. 37771150 ext. 33218, http://148.202.248.171/dugesiana/index.php/DUG/index, glenusmx@gmail.com. Editor responsable: José Luis Navarrete-Heredia. Reserva de Derechos al Uso Exclusivo 04-2009-062310115100-203, ISSN: 2007-9133, otorgados por el Instituto Nacional del Derecho de Autor. Responsable de la última actualización de este número: José Luis Navarrete-Heredia, Editor y Ana Laura González-Hernández, Asistente Editorial. Fecha de la última modificación 1 de enero 2020, con un tiraje de un ejemplar.

Las opiniones expresadas por los autores no necesariamente reflejan la postura del editor de la publicación.

Queda estrictamente prohibida la reproducción total o parcial de los contenidos e imágenes de la publicación sin previa autorización de la Universidad de Guadalajara. 


\title{
Moscas blancas (Hemiptera: Aleyrodidae) en México: estatus, especies, distribución e impor- tancia
}

\author{
Whiteflies (Hemiptera: Aleyrodidae) in Mexico: status, species, distribution and importance
}

\section{Laura Delia Ortega Arenas ${ }^{1 *}$ y Vicente Emilio Carapia Ruiz ${ }^{2}$}

${ }^{1}$ Posgrado en Fitosanidad - Entomología y Acarología, Campus Montecillo, Colegio de Postgraduados. Km. 36.5 Carretera México-Texcoco, Montecillo, Texcoco, Estado de México 56230, México. *ladeorar@colpos.mx; ${ }^{2}$ Escuela de Estudios Profesionales de Xalostoc (EESuX), Universidad Autónoma del Estado de Morelos (UAEM). Av. Nicolás Bravo s/n, Parque Industrial Cuautla, Xalostoc Ayala, Morelos 62715, México.

\section{RESUMEN}

Los aleiródidos o moscas blancas comprenden una sola familia, Aleyrodidae, dentro de Sternorrhyncha, el cual es uno de los tres subórdenes de Hemiptera. A nivel mundial se reconocen alrededor de 1564 especies válidas, agrupadas en tres subfamilias: Udamoselinae, Aleurodicinae y Aleyrodinae. La fauna del mundo existente de Aleyrodidae se asocia casi exclusivamente con plantas dicotiledóneas, con unas pocas especies en las angiospermas monocotiledóneas, particularmente de pastos y palmas. Esto sugiere que la diversificación de Aleyrodidae coincidió con el de las angiospermas en el Cretácico. Actualmente las moscas blancas ocurren en todas las regiones biogeográficas, pero son más diversas en regiones tropicales y subtropicales. Las especies de Aleyrodidae encontradas en México suman 130 incluidas en 29 géneros, sin embargo, dos especies de moscas blancas, la del tabaco o camote (Bemisia tabaci Genn.) y la de los invernaderos (Trialeurodes vaporariorum West.) representan las principales amenazas para la producción de muchos cultivos a nivel mundial, debido a su participación como vectores de virus en plantas.

Este documento tiene como objetivo proporcionar información concreta sobre el estado actual de las moscas blancas en México, haciendo especial énfasis en especies que representan amenazas para la producción de cultivos a nivel nacional.

Palabras Clave: Hemiptera, aleiródidos, mosca blanca del tabaco, mosca blanca de los invernaderos, mosca prieta de los cítricos.

\section{ABSTRACT}

Aleyrodids or whiteflies comprise a single family, Aleyrodidae, within Sternorrhyncha, which is one of the three sub-orders of Hemiptera. Globally, around 1564 valid species are recognized, grouped into three subfamilies: Udamoselinae, Aleurodicinae and Aleyrodinae. The existing world fauna of Aleyrodidae is associated almost exclusively with dicotyledonous plants, with a few species in monocotyledonous angiosperms, particularly grasses and palms. This suggests that the diversification of Aleyrodidae coincided with that of angiosperms in the Cretaceous. Whiteflies currently occur in all biogeographic regions, but are more diverse in tropical and subtropical regions. Aleyrodidae founded in Mexico add up to 130 species included in 29 genera, however, two species of whiteflies, tobacco or sweetpotato (Bemisia tabaci Genn.) and greenhouse (Trialeurodes vaporariorum West.) represent the main threats to production of many crops worldwide, due to their involvement as virus vectors in plants.

This document aims to provide concrete information on the current state of whiteflies in Mexico, with special emphasis on species that pose threats to crop production at the national level.

Key Words: Hemiptera, aleyrodids, sweetpotato whitefly, greenhouse whitefly, citrus blackfly.

La familia Aleyrodidae integra a un grupo de insectos conocidos como moscas blancas. Se caracteriza por tener una amplia distribución geográfica y gran número de hospederos, varias de estas especies se ubican en el "complejo mosca blanca", el cual está catalogado dentro de las primeras plagas agrícolas a nivel mundial. A la fecha se reconocen alrededor de 1564 especies válidas, agrupadas en tres subfamilias: Udamoselinae, Aleurodicinae y Aleyrodinae. La fauna del mundo existente de Aleyrodidae se asocia casi exclusivamente con plantas dicotiledóneas, con unas pocas especies en las angiospermas monocotiledóneas, lo cual sugiere que la diversificación de Aleyrodidae coincidió con el de las angiospermas en el Cretácico (Boykin et al. 2013; Ouvrard y Martin 2019).
En las áreas naturales, parques, jardines, huertos familiares y sobre todo en las zonas agrícolas es frecuente encontrar estas especies. En muchos de los casos se presentan formando parte del ecosistema, en equilibrio con sus enemigos naturales, pero en algunos otros pueden ocasionar daños que van desde niveles incipientes o leves, hasta severos o fuertes en los que pueden causar la muerte de las plantas (Martínez 1995; Horowitz et al. 2011).

Durante los últimos 100 años, dos especies de moscas blancas, la del tabaco o camote (Bemisia tabaci) y la de los invernaderos (Trialeurodes vaporariorum) parecían diferir de otras especies de importancia económica, desafiando los esfuerzos de control biológico y químico y convirtiéndose en plagas de gran importancia a escala internacional. Sin 
embargo, en últimas fechas se han estado realizando nuevos registros y las presentes han aumentado su adaptabilidad lo que favorece su dispersión hacia nuevos lugares antes libres de estas plagas. Con frecuencia, la aparición de especies exóticas en estas áreas da lugar a serios problemas, ya que las infestaciones se extienden con mayor rapidez e intensidad en ausencia de enemigos naturales eficaces. Las especies de Aleyrodidae encontradas en México suman 130 incluidas en 29 géneros, sin embargo, B. tabaci y $T$. vaporariorum representan las principales amenazas para la producción de muchos cultivos debido a su participación como vectores de virus en plantas (Carapia-Ruiz y Sánchez-Flores 2018).

A pesar de esto, poca financiación se ha otorgado para realizar estudios básicos sistemáticos que podrían facilitar el reconocimiento temprano de especies que logran pronto el estatus de plaga y causan un impacto económico negativo al establecerse en nuevas áreas geográficas.

Este documento tiene como objetivo proporcionar información concreta sobre el estado actual de las moscas blancas en México, haciendo especial énfasis en especies que representan amenazas para la producción de cultivos a nivel nacional, debido a su participación como vectores de virus en plantas.

\section{TAXONOMÍA Y DIAGNOSIS}

Los aleiródidos o moscas blancas comprenden una sola familia, Aleyrodidae, dentro de Sternorrhyncha, el cual es uno de los tres subórdenes de Hemiptera. A nivel mundial se reconocen alrededor de 1564 especies válidas y listadas en el catálogo de colección totalmente indexado del Museo de Historia Natural, Londres (BMNH) (Evans 2007 y 2008; Martin y Mound 2007; Ouvrard y Martin 2019).

Las primeras listas con descripción de especies de la familia Aleyrodidae corresponden a Kirkaldy (1907) y Quaintance (1908). Sin embargo, la división de esta familia en tres subfamilias, que se conserva hasta el presente, fue establecida por Quaintance y Baker $(1913,1914)$. Las tres subfamilias definidas son: Udamoselinae, Aleurodicinae y Aleyrodinae (Figura 1). La descripción de la subfamilia Udamoselinae se basó en un espécimen de América del Sur, un macho de $7 \mathrm{~mm}$ de largo corporal que aparentemente fue destruido (Mound y Halsey 1978). Al presente, la subfamilia Udamoselinae está representada por dos especies de Sudamérica incluidas en el género Udamoselis (Martin 2007).

La subfamilia Aleurodicinae es la más primitiva de las tres subfamilias, con 122 especies descritas, incluidas en 19 géneros, todas ellas de distribución tropical y subtropical. Tiene especies endémicas, sobre todo en América del Sur y Central. Los adultos presentan venación alar completa y se caracterizan porque presentan patas con uña apical y la exuvia o pupario presenta, casi siempre, sobre la superficie dorsal, de 5 a 8 pares de poros compuestos subdorsales, un par cefálico y 4 o 6 pares abdominales, especializados en la producción de ceras y porque la língula presenta cuatro setas normalmente grandes, aunque a veces dos son reducidas, regularmente rebasando el límite del orificio vasiforme. Llegan a medir hasta los $10 \mathrm{~mm}$ (Byrne y Bellows 1991; Evans 2007).

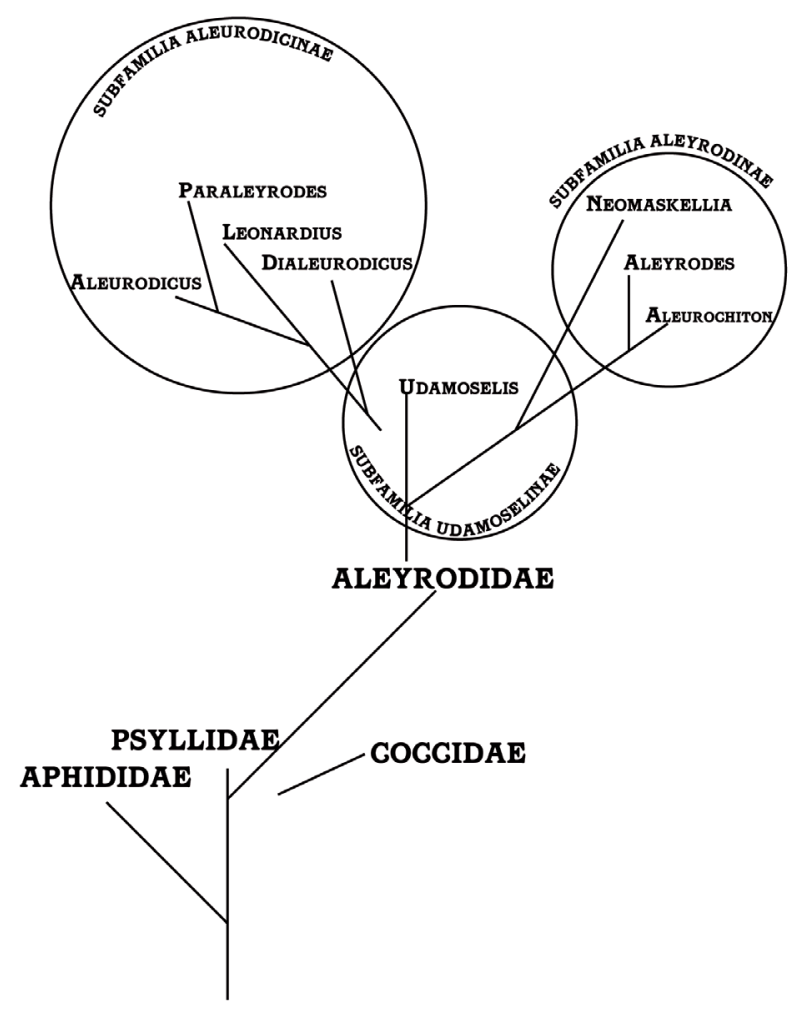

Figura 1. Diagrama genealógico de Aleyrodidae. Reelaborado por J.L. Navarrete-Heredia de Quaintance y Baker (1913). 
En la subfamilia Aleyrodinae es donde ha ocurrido la mayor diversificación de especies, y agrupa a más de 1440 especies válidas incluidas en 141 géneros. Los puparios o exuvias de Aleyrodinae se caracterizan porque, no presentan poros compuestos subdorsales, aunque en ocasiones presentan cinco pares de poros simples uniformemente separados, la língula es muy variable, aunque por lo general pequeña, en forma de lengua y sin las cuatro setas y adultos presentan patas con saco adhesivo apical. En esta subfamilia se incluyen la mayoría de especies de moscas blancas de importancia económica (Martin 1987).

\section{MORFOLOGÍA}

Las moscas blancas son insectos pequeños que miden de 1-3 mm (Aleyrodinae) a $7 \mathrm{~mm}$ (Aleurodicinae y Udamoselinae) de longitud corporal, de forma parecida a palomillas diminutas, por lo general de color blanquecino debido a la presencia de secreción pulverulenta sobre el cuerpo y alas de los adultos de casi todas las especies. En reposo, las alas permanecen en forma plana sobre el cuerpo. Tienen tarsos de dos segmentos, antenas filiformes de siete segmentos, ojos compuestos de forma arriñonada y un par de ocelos situados cerca del borde superior de los ojos (Martin 2007; Ortega 1995 y 2008).

Los adultos de Aleyrodidae no presentan variaciones muy evidentes en las características morfológicas externas entre las especies, por lo que para la separación de éstas se utilizan las características morfológicas del cuarto instar ninfal "pupa" o de su exuvia (Evans 2007 y 2008).

Una estructura conocida como orificio vasiforme es única en Aleyrodidae y abarca el ano, una língula, para la expulsión de excrementos líquidos, y un opérculo que cubre parcial o totalmente el orificio vasiforme. El orificio vasiforme está presente en todas las etapas ninfales, así como en los adultos, proporcionando un carácter simple de reconocimiento de moscas blancas en cualquier etapa de su ciclo de vida (Ortega 1995; Shahab y Quicke 2006; Evans 2007 y 2008) (Figura 2).

\section{ORIGEN Y DISTRIBUCIÓN}

Las moscas blancas pertenecen a un grupo de distribución mundial que en la mayoría de las especies corresponde a la parte intertropical. Se considera que los aleiródidos son el equivalente tropical de los áfidos de zonas templadas. Mound y Halsey (1978) consideran nueve regiones zoogeográficas de distribución de moscas blancas: Paleártica, Etiópica, Madagascar, Oriental, Australia-Asia, Pacífico, Neártica y Neotropical. La subfamilia Aleurodicinae ocurre casi en su totalidad a la región Neotropical, en la que 15 de los 19 géneros y 84 de las 122 especies corresponden a esta zona. Bink-Moenen y Mound (1990) proporcionan una correlación del número de especies de Aleyrodidae con respecto a la latitud en Europa de la siguiente forma: latitud en grados-número de especies, 65-3, 60-10, 55-12, 50-17, 45-25, 40-33, 35-32. Existen géneros muy numerosos dis- tribuidos en todo el mundo (Aleurotrachelus, Aleuroplatus y Tetraleurodes); sin embargo, la mayoría está restringida a una sola región.

De acuerdo a la región donde se han colectado la mayoría de las especies y a las opiniones de los especialistas del grupo, se infiere el probable origen de ciertos géneros; por ejemplo, Trialeurodes Cockerell es del nuevo mundo, particularmente el suroeste de Estados Unidos y noroeste de México, aunque hoy la distribución de este género es mundial (Russell 1948). De acuerdo con Mound (1984) el número de especies de Trialeurodes para las distintas regiones zoogeográficas tiene la siguiente distribución: para la Neártica (29), Neotropical (14), Madagascar (2), Afro tropical (3), Pacífico (3), Australia (1), Austraoriental (6), Oriental (9), y Paleártica (4). Es clara la importancia de América respecto al número de especies de Trialeurodes, más aún si se considera que algunas de éstas, como T. mameti Takahashi de la Isla Reunión (Takahashi 1951), T. perakiensis Corbett y T. palaquifoliae Corbett de Malasia (Corbett 1935), presentan características que no son propias del género y probablemente deban ser incluidas en otros (Mound 1984).

Evans (2007) publicó una lista de especies de mosca blanca del mundo en la que incluye 1560 especies incluidas en 168 géneros pertenecientes a las subfamilias Aleurodicinae y Aleyrodinae. La subfamilia Aleurodicinae se distribuye en el nuevo mundo e incluye 122 especies en 19 géneros. La subfamilia Aleyrodinae tiene distribución mundial e incluye 1438 especies en 150 géneros (Cuadro 1).

\section{ESPECIES DE ALEYRODIDAE EN MÉXICO}

Cockerell $(1898,1902)$ reportó una breve sinopsis de Aleyrodidae para México, posteriormente Quaintance y Baker (1913) en uno de los primeros trabajos taxonómicos integrales de Aleyrodidae del mundo incluyeron algunas especies de México. Dos contribuciones importantes de la familia Aleyrodidae fueron realizadas para la República Mexicana por Baker (1937) quién reportó 32 especies y Sampson y Drews (1941) quienes registraron 41 especies. Recientemente contribuciones a las moscas blancas de México se han realizado para Aleurodicus Martin (2008); Bemisia Carapia-Ruiz et al. (2009a); Cuautlaleyrodes Carapia-Ruiz et al. (2009b); Paraleyrodes Carapia y Castillo (2011), Carapia-Ruíz et al. (2013); Aleurodicinae, Carapia-Ruíz et al. (2016); Trialeurodini Carapia-Ruíz et al. (2017); Aleuroparadoxus Sánchez-Flores et al. (2017a); Tetraleurodes Carapia-Ruiz et al. (2017), Sánchez-Flores et al. (2017b); Aleurothrixus Sánchez-Flores et al. (2018a); Aleuropleurocelus Carapia-Ruiz et al. (2018a, b, c), Sánchez-Flores et al. $(2018 \mathrm{~b}, \mathrm{c})$.

Recientemente Sánchez-Flores et al. (2018) describieron Aleurovitreus pueblensis (A. risor), A. tuberculatus, A. piperschiedeanu, mientras que Sánchez-Flores y Carapia-Ruiz (2018) describieron a Aleuropleurocelus chamaedoraelegans y A. mixtecus (Carapia-Ruiz 2019 en prensa) y Carapia-Ruiz (2019 en prensa) a Aleurotithius romeronapolesi. Varias especies [Aleuropleurocelus cecro- 

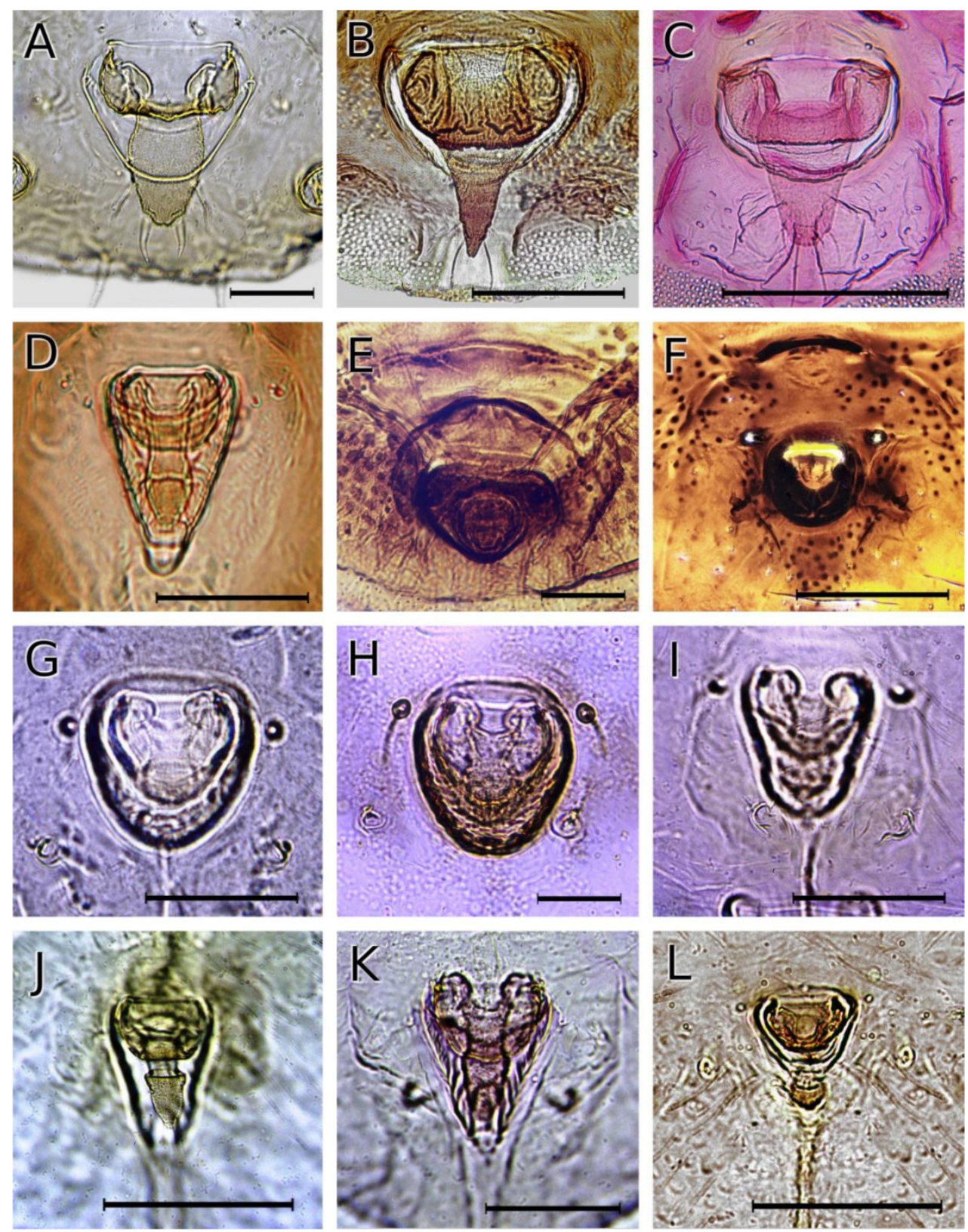

Figura 2. Formas del orificio vasiforme en Aleyrodidae. A) Paraleyrodes minei; B) Aleurodicus rugioperculatus; C) Aleurodicus floccissimus; D) Aleurocibotus occiduus; E) Aleuropleurocelus sp.; F) Aleuroplatus coronata; G) Trialeurodes bellissima; H) Trialeurodes multipori; I) Trialeurodes vaporariorum; J y K) Bemisia tabaci; L) Singhiella simplex. Escala 200 m. (Imágenes L. Ortega y J. Valdez). 
Cuadro 1. Número y distribución de especies y géneros de Aleyrodidae por región zoogeográfica (Evans 2007).

\begin{tabular}{|c|c|c|c|c|c|c|c|c|c|c|c|}
\hline & $\begin{array}{l}\text { Mun- } \\
\text { dial }\end{array}$ & $\begin{array}{l}\text { Neár- } \\
\text { tica }\end{array}$ & $\begin{array}{c}\text { Neotro- } \\
\text { pical }\end{array}$ & $\begin{array}{l}\text { Paleárti- } \\
\text { ca Occi- } \\
\text { dental }\end{array}$ & $\begin{array}{c}\text { Afrotro- } \\
\text { pical }\end{array}$ & $\begin{array}{l}\text { Paleár- } \\
\text { tica } \\
\text { Oriental }\end{array}$ & $\begin{array}{l}\text { Orien- } \\
\text { tal }\end{array}$ & Australasia & $\begin{array}{c}\text { Islas } \\
\text { Pacífico }\end{array}$ & Hawái & Fósil \\
\hline \multicolumn{12}{|c|}{ SUBFAMILIA ALEURODICINAE } \\
\hline $\begin{array}{l}\text { Total } \\
\text { espe } \\
\text { cies }\end{array}$ & 122 & 12 & 106 & 6 & 5 & 3 & 9 & 10 & 4 & 122 & \\
\hline $\begin{array}{l}\text { Total } \\
\text { géne- } \\
\text { ros }\end{array}$ & 18 & 5 & 14 & 6 & 3 & 2 & 3 & 4 & 3 & 2 & \\
\hline \multicolumn{12}{|c|}{ SUBFAMILIA ALEYRODINAE } \\
\hline $\begin{array}{l}\text { Total } \\
\text { espe } \\
\text { cies } \\
\end{array}$ & 1438 & 124 & 212 & 137 & 284 & 256 & 543 & 132 & 71 & 24 & 1 \\
\hline $\begin{array}{l}\text { Total } \\
\text { géne } \\
\text { ros }\end{array}$ & 150 & 29 & 42 & 41 & 54 & 51 & 73 & 43 & 28 & 18 & 1 \\
\hline
\end{tabular}

piae, A. coachellensis, A. oblanceolatus (A. granulata), A. rotunda (A. abnormis), A. laingi, Trialeurodes eriodictio$n i]$, encontradas en México por Carapia-Ruiz se encuentran en proceso de registro.

Las especies de Aleyrodidae encontradas en México suman 130 incluidas en 29 géneros (Carapia-Ruiz y Sánchez-Flores 2018) (Cuadro 1) casi la totalidad de ellas se tiene en las colecciones a resguardo de los dos autores (VECR, OASF); un considerable número de especies no han sido descritas en América tropical (Martin 2005) y en México, varias especies de los géneros Aleuroparadoxus, Aleuroplatus, Aleurovitreus, Aleuropleurocelus, Tetraleurodes, se encuentran en proceso de descripción.

En las Figuras 3 y 4 se ilustran ninfas de $4^{\circ}$ instar representantes de los géneros y especies de Aleyrodidae citados en México.

\section{BIOLOGÍA Y ECOLOGÍA}

Las moscas blancas son insectos succionadores que se localizan en el envés de las hojas de sus hospedantes. Presentan metamorfosis incompleta; es decir que su ciclo biológico incluye una etapa de huevo, cuatro estadios ninfales y el adulto (Figura 5). Al primer estadio ninfal usualmente se le denomina "larva" o "gateador" y al último estadio "pupa" (Butler 1982; Byrne et al. 1990; Gill 1990). La hembra oviposita en el envés de la hoja. Los huevos tienen forma de huso y en su parte basal llevan un pedicelo corto que les sirve para anclarse en la hoja. El número máximo varía de 48 a 500 según la especie, las condiciones ambientales y la planta hospedante (Butler 1982; Byrne et al. 1990; Gill 1990; Byrne y Bellows 1991). Cuando termina el desarrollo del huevo, se rompe por la parte apical, por donde sale o emerge una ninfa en forma de escama. La ninfa se mueve por un tiempo corto para seleccionar un sitio de alimentación. Después de que la ninfa comienza a alimentarse, pasa por otras tres etapas o ínstares ninfales de desarrollo, en cada caso de mayor tamaño, hasta transformarse en el adulto (Butler 1982; Byrne et al. 1990; Gill 1990).

Pocas horas después de la emergencia, los machos adultos están aptos para iniciar el cortejo. Copulan varias veces y las hembras presentan mayor longevidad que los machos. El ciclo de vida de huevo a adulto puede completarse en dos a tres semanas en climas calientes, pero puede requerir hasta de dos meses en climas fríos. Presentan de 11 a 15 generaciones al año con reproducción predominantemente sexual, aunque pueden reproducirse por partenogénesis. Las temperaturas altas acortan la duración del ciclo y las bajas lo alargan (Byrne y Bellows 1991). De manera general, las tasas de desarrollo se incrementan al aumentar la temperatura hasta los $30^{\circ} \mathrm{C}$ y luego decrecen a partir de los $32{ }^{\circ} \mathrm{C}$. T. vaporariorum es afectada por temperaturas extremas $\left(>35^{\circ} \mathrm{C}\right)$ y alta humedad, y detiene su desarrollo a $8{ }^{\circ} \mathrm{C}$. La temperatura umbral mínima para el desarrollo de huevo a adulto, para varias especies de aleiródidos, varia de 10 a $13.2{ }^{\circ} \mathrm{C}$ y requieren de 250 a 315 unidades calor (UC) para completar su desarrollo (Nava-Camberos et al. 2001).

\section{PLANTAS HOSPEDERAS}

La fauna del mundo existente de Aleyrodidae se asocia casi exclusivamente con plantas dicotiledóneas, con unas pocas especies en las angiospermas monocotiledóneas, particularmente de Arecaceae, Cyperaceae, y Poaceae. Esto sugiere que la diversificación de Aleyrodidae coincidió con el de las angiospermas en el Cretácico (Mound y Halsey 1978; Mound et al. 1994; Campbell et al. 1995; Boykin et al. 2013).

La mayoría de las moscas blancas tienen hábitos polífagos; es decir, que se alimentan, refugian o desarrollan en un gran número de especies vegetales tanto cultivadas como silvestres, aunque muestran preferencia a plantas de las 

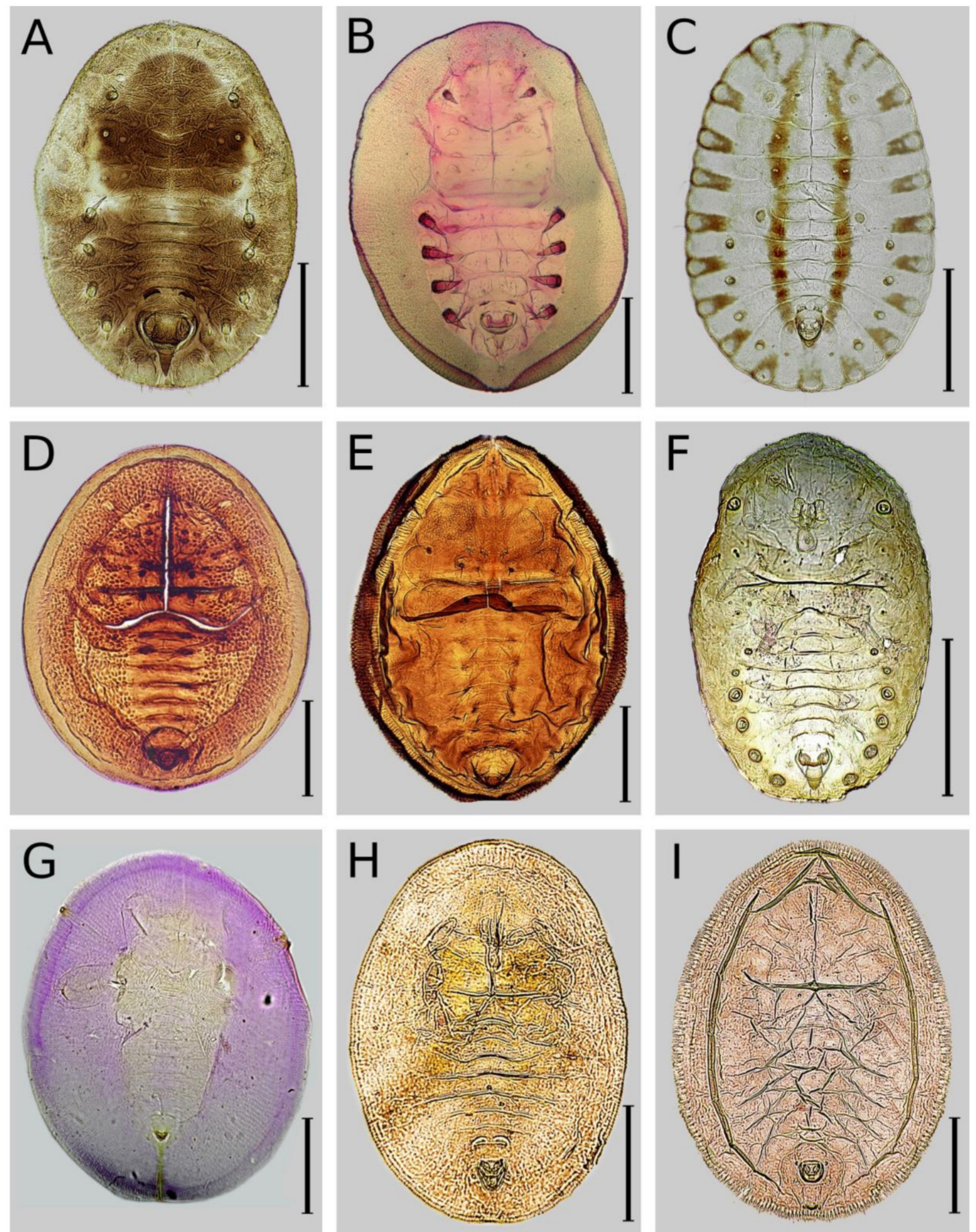

Figura 3. Ninfas de $4^{\circ}$ instar representantes de los géneros y especies de Aleyrodidae citados en México. A) Aleurodicus rugioperculatus; B) Aleurodicus floccissimus; C) Nealeurodicus altissimus; D) Aleuropleurocelus sp.; E) Tetraleurodes perseae; F) Paraleyrodes minei; G) Singhiella simplex; H) Aleyrodes sp.; I) Aleurothrixus floccosus. Escala 500 ㅆm. (Imágenes L. Ortega y J. Valdez). 

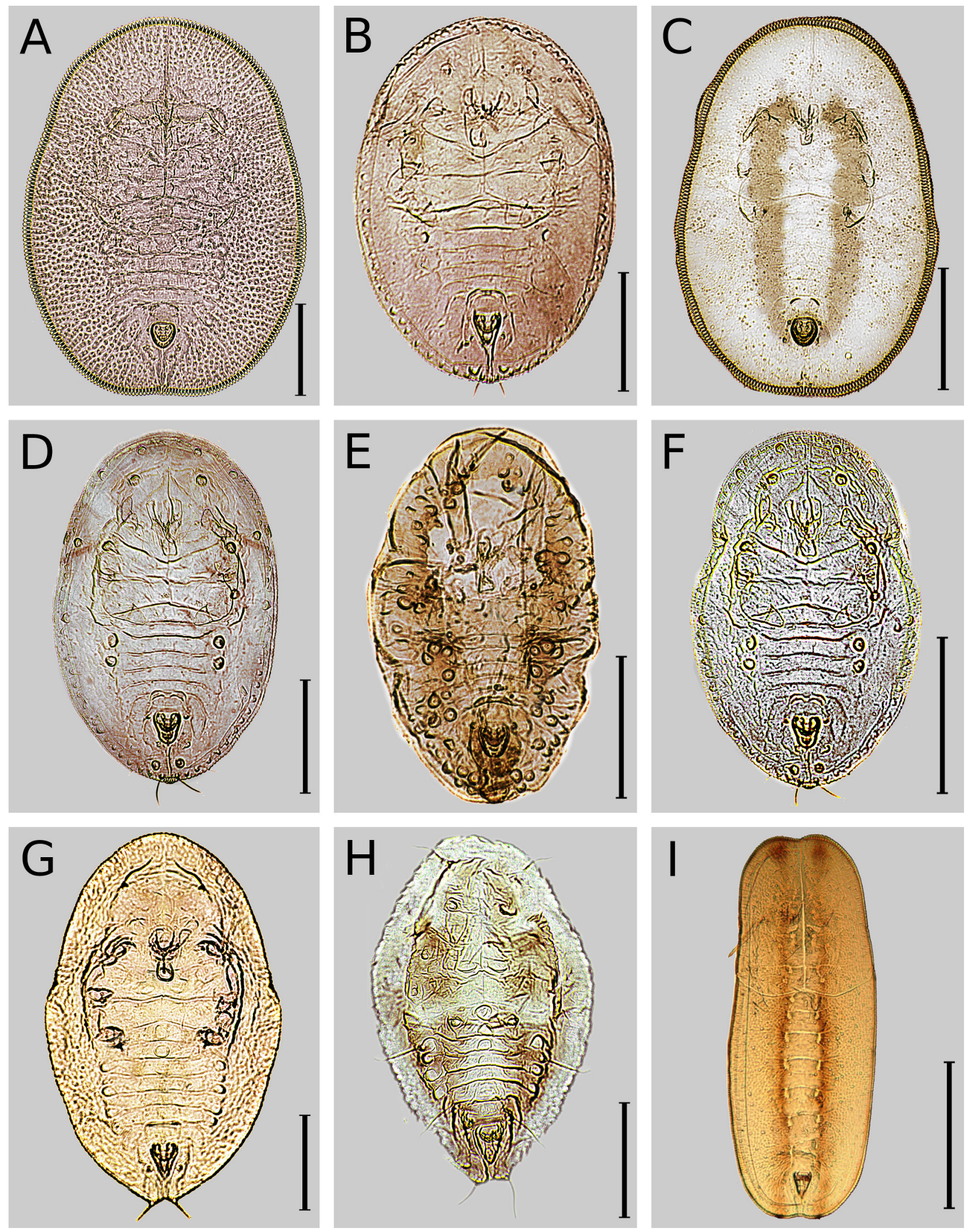

Figura 4. Ninfas de $4^{\circ}$ instar representantes de los géneros y especies de Aleyrodidae citados en México. A) Trialeurodes bellissima; B) Trialeurodes vaporariorum; C) Trialeurodes multipori; D) Trialeurodes vaporariorum; E) Trialeurodes tephrosiae; F) Trialeurodes vaporariorum; G) Bemisia tabaci; H) Bemisia tabaci; I) Aleurocibotus occiduus. Escala 500 m. (Imágenes L. Ortega y J. Valdez). 


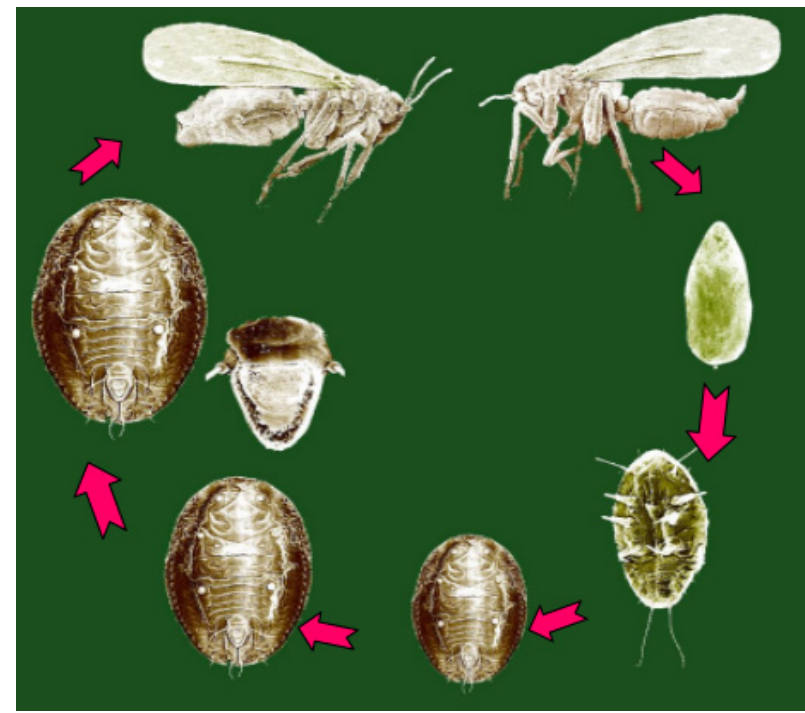

Figura 5. Ciclo biológico de Trialeurodes vaporariorum (L. Ortega y J. Valdez).

familias Asteraceae, Brassicaceae, Cucurbitaceae, Euphorbiaceae, Fabaceae, Lamiaceae, Malvaceae y Solanaceae (van Lenteren y Noldus 1990; Bayhan et al. 2006; Xu et al. 2011; Shah y Liu 2013). De este modo, la oportunidad de encontrar una hospedante dónde concluir su ciclo biológico y dar continuidad a su especie es muy alta. Atacan a más de 600 especies de plantas hospedantes, lo cual incluye plantas cultivadas y no cultivadas, anuales y perennes (Secker et al. 1998; Martin et al. 2000; Naranjo y Ellsworth 2009).

Las moscas blancas, al igual que todos los insectos cuyos estados inmaduros son sésiles, están sujetas a una fuerte presión de selección para elegir aquellas especies o partes de plantas que son las más adecuadas para alimentarse y ovipositar (van Lenteren y Noldus 1990). El proceso de selección es mediado por estímulos visuales, gustativos y olfatorios (van Lenteren y Noldus 1990; Gerling 2002).

La oviposición ocurre antes de la ingestión de savia y probablemente sucede cuando los estiletes han traspasado la epidermis o alcanzado las células del mesófilo. La correcta elección de la hospedante durante la oviposición es determinante para las hembras y su progenie. Las moscas blancas pueden detectar "leer" el empobrecimiento en la calidad nutritiva de la planta hospedante, y elegir cambiar su ruta metabólica o simplemente moverse hacia plantas más vigorosas (van Lenteren y Noldus 1990; Isaacs y Byrne 1998; Gerling 2002).

Cada especie vegetal moviliza tipos específicos de azúcares en el floema. Las plantas de algodón movilizan sacarosa, mientras que las cucurbitáceas movilizan azúcares que contienen galactosa, como rafinosa o estaquitosa (Salvucci et al. 1997). Puesto que las moscas blancas se alimentan del floema, deben desdoblar estos azúcares para utilizarlos, así como para descartar el exceso, transformándolos en otros oligosacáridos, como la trehalosa (Gerling 2002). Cuando hay migraciones desde calabazas a melones (que usan rafinosa y estaquitosa) a algodón (que usa sacarosa), el insecto también debe cambiar su ruta metabólica, utilizando dife- rentes enzimas para desdoblar los azúcares (Salvucci et al. 1997; Gerling 2002).

\section{IMPORTANCIA COMO PLAGAS}

Las moscas blancas continúan siendo una de las plagas más problemáticas del mundo. Son causa de grandes pérdidas en cultivos debido a su forma de alimentación y, de manera indirecta, por ser vector de virus en plantas (Horowitz et al. 2011). El comercio internacional de esquejes, plantas y frutos de especies susceptibles de ataque por mosca blanca y por los virus asociados a este insecto favorece su dispersión hacia nuevos lugares antes libres de esta plaga. A menudo, la aparición de nuevas especies en estas áreas da lugar a serios problemas, ya que las infestaciones se extienden con mayor rapidez e intensidad en ausencia de enemigos naturales eficaces. El movimiento de moscas blancas hacia nuevas zonas geográficas puede también originar otros problemas, como es la selección de genes de resistencia a insecticidas en estas nuevas poblaciones (Boykin et al. 2013).

Las moscas blancas tienen un aparato bucal picador succionador con el cual ellas pinchan la hoja y succionan los fluidos de las plantas. Los síntomas más notables resultantes de una infestación de moscas blancas son la presencia abundante del material ceroso y blanco que recubre las hojas así como la melaza, una substancia azucarada que sirve de sustrato para el crecimiento de un hongo de color negro conocido como "fumagina" (Figura 6).

Las hojas de los árboles infestados comienzan a amarillear y defoliarse. Además de la defoliación, puede haber muerte regresiva de ramas. La intensidad del daño es variable y probablemente está relacionada con la salud general de la planta (Ortega 2008). Sin embargo, el daño más importante de las moscas es cuando actúan como vectores de virus. Los síntomas de infecciones causadas varían de acuerdo al virus y a la cepa, el cultivar, la edad de la planta al momento de la infección y las condiciones ambientales. Estos insectos son capaces de transmitir más de 40 agentes causales de enfermedades, que se caracterizan por inducir amarillamientos severos, moteados y mosaicos cloróticos, achaparramientos, rizado de las hojas, deformación de las hojas, arrugas o pliegues en las hojas, además de promover el aborto de flores y causar deformaciones en el fruto (Rivas 1994; Polston y Anderson 1999).

Los principales virus que transmiten las moscas blancas son del grupo de los geminivirus (poliedros de DNA en pares) y los carlavirus, closteovirus y potyvirus, que se caracterizan por presentar forma de varilla flexible. Se han desarrollado diferentes pruebas moleculares para la determinación de los virus transmitidos por las moscas blancas (De Barro et al. 2011; Romay et al. 2016).

\section{ESPECIES IMPORTANTES \\ Bemisia tabaci (Gennadius, 1889)}

La mosca blanca Bemisia tabaci, también conocida como la mosca blanca del algodón, del tabaco o de la ba- 


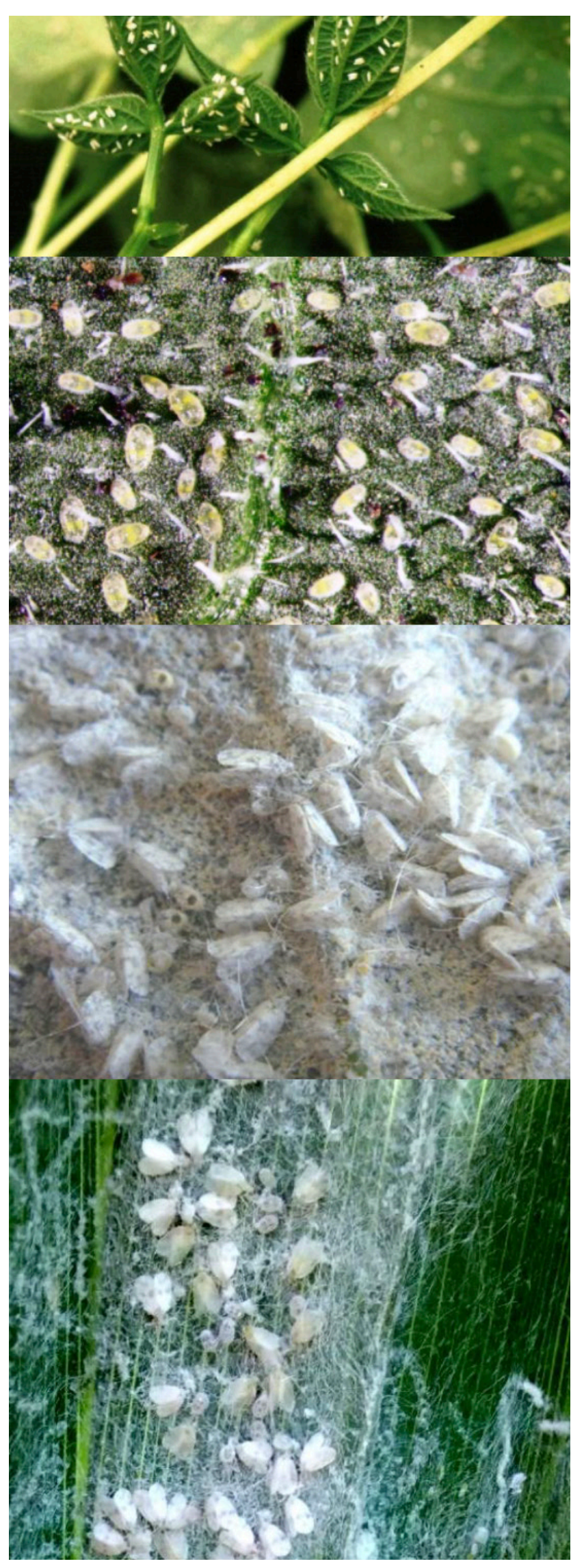

Figura 6. Infestación de moscas blancas en varias hospederas (L. Ortega). tata, fue originalmente descrita en Grecia como Aleyrodes tabaci (Gennadius, 1889). En el Nuevo mundo fue recolectada por primera vez en 1897 sobre Ipomoea batatas (L.) Lam. en los Estados Unidos, donde se describió como Aleyrodes inconspicua Quaintance (Quaintance 1900). En 1957 esta especie y otras 18 fueron incluidas en un sólo taxón: B. tabaci (Russell 1957) (Figura 7).

Entre los años 1926 y 1981, B. tabaci fue citada como una plaga esporádica y señalada como el vector más importante de virosis afectando importantes cultivos en las zonas tropicales y subtropicales (Brown y Bird 1992; Brown et al. 1995; Polston y Anderson 1999).

Algunos científicos sugieren que $B$. tabaci puede ser originaria de África tropical, desde donde se dispersó a Europa y Asia, y fue posteriormente introducida al Neotrópico, principalmente por movilización de material vegetal (Brown y Bird 1992; Campbell et al. 1995). Sin embargo, otros científicos sugieren que esta especie puede ser nativa de India o Pakistán, donde se ha encontrado la mayor diversidad de especies de sus enemigos naturales (Brown et al. 1995). B. tabaci se extiende en una diversidad de sistemas agrícolas, desde subtropicales hasta tropicales, pero también ocurre en áreas de climas templados. Es una especie distribuida globalmente y se encuentra en todos los continentes con excepción de la Antártica (Martin et al. 2000; Oliveira et al. 2001).

B. tabaci ha sido registrada alimentándose de más de 600 especies de plantas hospederas (Mound y Halsey 1978; Secker et al. 1998). Estas especies se ubican en 74 familias, incluyendo hortalizas, plantas ornamentales, cultivos industriales y numerosas especies silvestres. Entre los hospederos atacados por este insecto se encuentran comúnmente plantas que pertenecen a las familias Brassicaceae, Cucur-

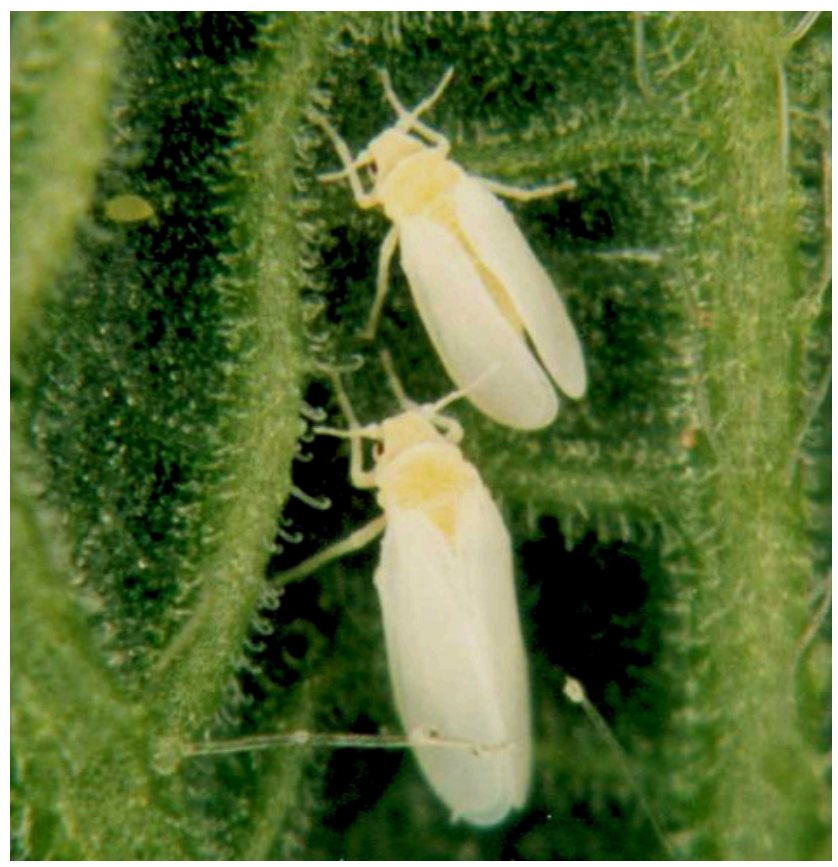

Figura 7. Adultos de B. tabaci (J. Djair). 
bitaceae, Fabaceae y Solanaceae (Brown 1993). Aunque B. tabaci ha sido considerada como una especie polífaga, se han descubierto poblaciones monófagas (Brown et al. 1995; Perring 2001; Thompson 2003).

En 1986 se encontró una nueva forma de B. tabaci en plantas de poinsettia o nochebuena (Euphorbia pulcherrima Willd.) mantenidas en invernaderos del estado de La Florida (Brown et al.1995). Esta nueva forma, llamada biotipo "poinsettia" o biotipo B, se introdujo al suroeste de los Estados Unidos, rápidamente reemplazando la forma original, el biotipo A (Chu et al. 2010; Teng et al. 2010; Pan et al. 2012). Para 1991, el biotipo B había causado millones de dólares de pérdidas en los cultivos de California y Arizona (Anderson 2000). Se ha demostrado que el biotipo B posee un rango más amplio de plantas hospedantes (Brown et al. 1995), una fecundidad mayor que la del biotipo A (Bethke et al. 1991), ingiere una mayor cantidad de savia del floema de las plantas durante la alimentación y consecuentemente excreta un mayor volumen de melaza que el biotipo A (Byrne y Miller 1991); además, a diferencia del biotipo A, el biotipo $\mathrm{B}$ induce desórdenes fisiológicos y es más eficiente en la transmisión de virus (McAuslane et al. 2004; Pan et al. 2012; Liu et al. 2012). Con base en datos experimentales biológicos, morfológicos y genéticos, utilizando poblaciones de Bemisia de California, Perring et al. (1993) y Bellows et al. (1994), concluyeron que los biotipos A y B eran especies distintas denominando el biotipo B como Bemisia argentifolii (Bellows y Perring). Sin embargo, esta conclusión no ha sido sustanciada al estudiar más ampliamente las poblaciones de B. tabaci del Viejo y Nuevo Mundo (Brown et al. 1995). Adicionalmente, estudios filogenéticos y reproductivos realizados por Campbell et al. (1995) entre los dos biotipos, no soportan la existencia de dos especies. Por consiguiente, se considera que solo existe una especie, Bemisia tabaci (Gennadius) como un complejo de biotipos (Anderson 2000).

Estudios recientes sugieren que $B$. tabaci es un complejo conformado por más de 30 especies crípticas morfológicamente indistinguibles (Xu et al. 2010; De Barro et al. 2011; Boykin et al. 2013; Lee et al. 2013). Las dos especies más invasivas y destructivas son las nominadas como biotipo B y Q, respectivamente (De Barro et al. 2011; Pan et al. 2012).

De las especies de Aleyrodidae presentes en México, " $B$. argentifolii o biotipo B" o mosca blanca de las hojas plateadas (MBHP) (Figura 8) es la que ha ocasionado el mayor impacto económico, principalmente en los cultivos de algodonero (Gossypium hirsutum L.), melón (Cucumis melo L.), calabaza (Cucurbita pepo L.), sandía [Citrullus lanatus (Thunb.) Mansf], pepino (Cucumis sativus L.), lechuga (Lactuca sativa L.), rábano (Raphanus sativus L.), jitomate (Solanum lycopersicum L.), chile (Capsicum annuum L.), col (Brassica oleraceae L.), okra [Abelmoschus esculentus (L.) Moench], soya (Glycine max (L.), fríjol (Phaseolus vulgaris L.), naranja (Citrus sinensis L.), camote [Ipomoea batatas (L.) Lam.], cacahuate (Arachis hypogaea L.) y no-

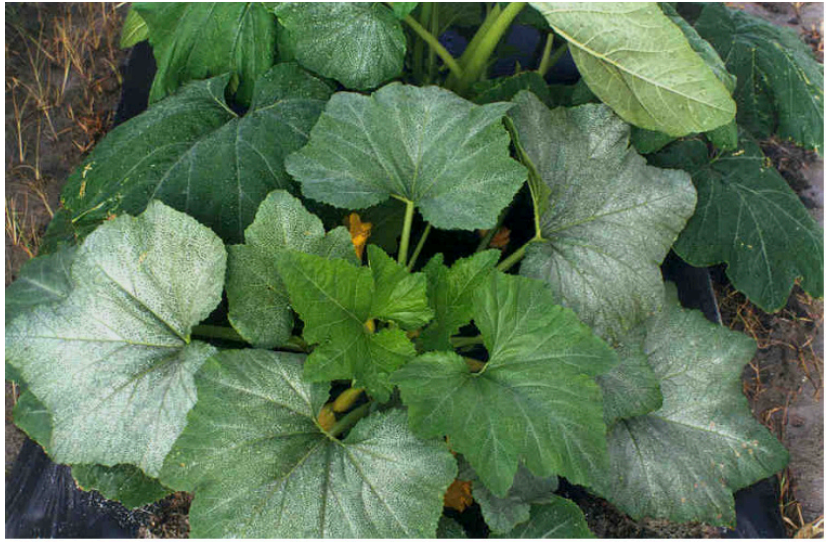

Figura 8. Planta de calabaza con síntomas de plateado (L. Ortega).

chebuena (DGSV-SAGAR 1995; Martínez 1995; León et al. 1996; Martínez y Brown 2007).

En México, durante 1991, la MBHP se presentó como un verdadero problema fitosanitario en el Valle de Mexicali, B.C.; la región de San Luis Rio Colorado, Sonora; la Comarca Lagunera, Coahuila y en la Costa de Hermosillo, Sonora. En estas localidades durante el otoño de 1992, esta plaga afectó los cultivos de algodonero, melón, sandía, y ajonjolí (Sesamum indicum L.), provocando pérdidas económicas estimadas en 100 millones de pesos (León 1993; Martínez 1995; León et al. 1996; Martínez y Brown 2007).

Su combate requirió un elevado uso de insecticidas. Actualmente las poblaciones de $B$. tabaci detectadas son bajas, a nivel nacional. Sin embargo, sobre todo varias hortalizas han manifestado en forma importante los efectos de enfermedades virales, caracterizadas por síntomas de amarillamiento y arrugamiento del follaje, asociados con altas poblaciones del vector. En el noroeste de México, $B$. tabaci biotipo $\mathrm{B}$ transmite el virus de la hoja enrollada de la calabaza, la cual es la principal limitante para su producción; se estima que los rendimientos de calabaza pueden ser afectados entre 50 y 100\% (León 1993; Martínez 1995; León et al. 1996).

Trialeurodes vaporariorum (Westwood, 1856)

Uno de los principales centros de diversificación de Aleyrodidae es indudablemente la región tropical de América, en donde existe un considerable número de especies y probablemente de géneros aún sin describir. Dentro de los más conocidos se encuentra Trialeurodes, género conocido básicamente de América, como lo demuestra la mayor parte de las especies descritas, de las cuales, 56 son citadas por Mound y Halsey (1978), una por Rapisarda (1985), una por Russell (1943), dos por Martín (1999) y dos más por Martín y Camus (2001), haciendo un total de 62 especies para el mundo. En México, Cockerell (1902) en un breve trabajo de Aleyrodidae, incluyó a Aleyrodes nicotianae ( $T$. vaporariorum), y después en 1909 a Aleyrodes vitrinellus (T. vitrinellus). Baker (1937) describió a T. mirissimus y Russell (1948) a 34 especies del género Trialeurodes para América del Norte de las cuales T. vitrinellus, T. coccolo- 
bae, T. oblongifoliae, T. mirissimus, T. variabilis, T. tephrosiae, T. vaporariorum, T. varia y T. abutilonea son citadas para México. Carapia et al. (2003) y Carapia $(2006,2007)$ registraron decenas de especies, cinco especies nuevas para la ciencia y cuatro nuevos registros para México. El hecho de que en últimas fechas se estén realizando nuevos registros, indica que en México aún se encuentra un considerable número de especies de moscas blancas por conocer.

Trialeurodes vaporariorum (Westwood), también conocida como mosca blanca de los invernaderos, es originaria de América, particularmente de Estados Unidos y del noroeste de México. Esta plaga se encuentra distribuida en las regiones tropicales y subtropicales del mundo, fue descrita por primera vez como Aleyrodes vaporariorum en Inglaterra en 1856 y considerada por Russell (1948) como endémica del sudoeste de Estados Unidos, registrándola también en América del Sur: Perú, Colombia, Ecuador, Guyana, Brasil, Chile y Argentina en 1870 (Figuras 9 y 10).

Esta especie se ha registrado en más de 250 especies de plantas y en la mayoría de cultivos de importancia económica. Entre los principales hospederos están el frijol, tomate, pepino, chile o pimiento, calabaza, berenjena (Solanum melongena L.), papa (Solanum tuberosum L.) y algodón.

Todos los estadíos de este insecto, excepto el huevo, causan daños en los cultivos por acción directa de su ali-

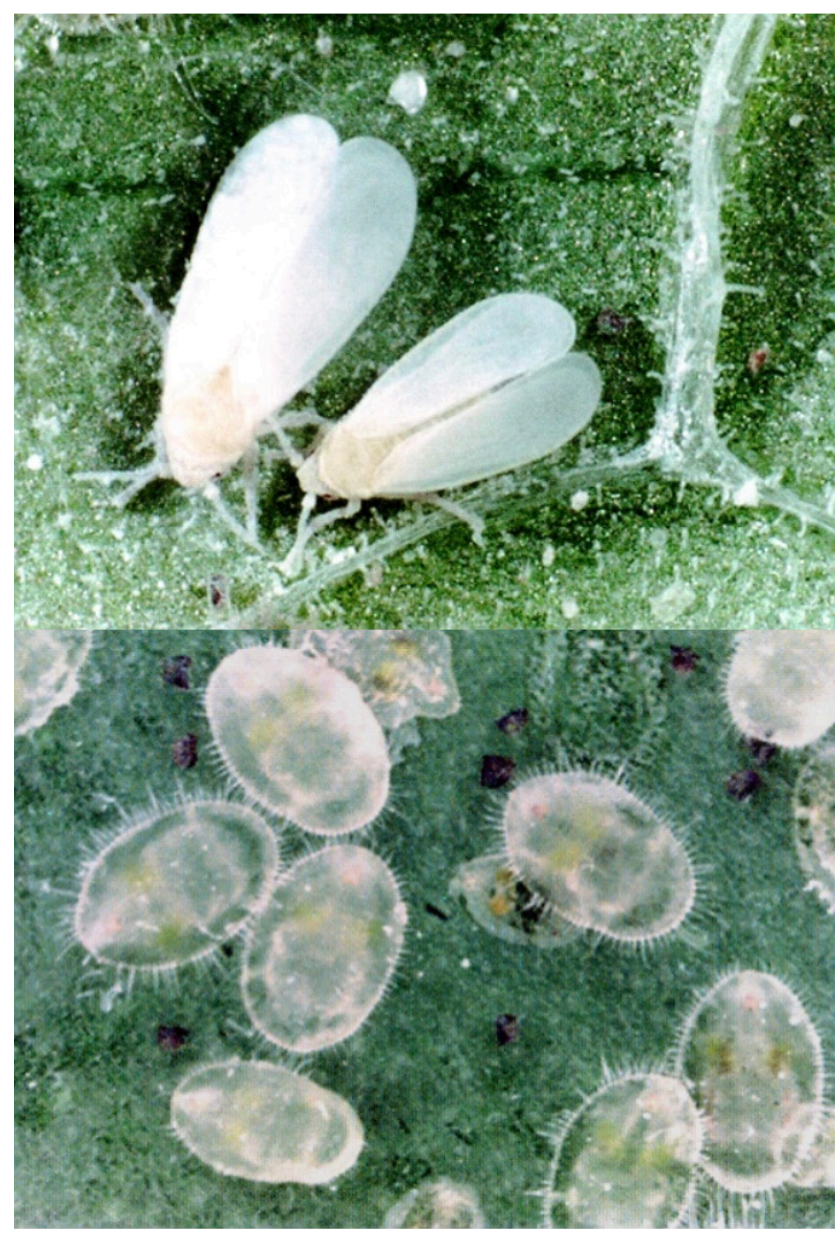

Figura 9. Adultos y ninfas de Trialeurodes sp. (F. García y L. Ortega). mentación ya que insertan su estilete en los vasos conductores de savia y la extraen. Un subproducto de su alimentación es la mielecilla que segregan por el ano, esta sustancia azucarada queda depositada en las hojas y sobre ella se pueden desarrollar hongos de coloración negruzca, normalmente conocidos como fumagina (Johnson et al. 1982). T. vaporariorum ha ganado notoriedad como vector de virus de plantas sólo en las últimas dos décadas, en especial en las regiones templadas. Sin embargo, esta especie de mosca blanca ahora muestra capacidad para transmitir crinivirus en las tierras altas tropicales de América del sur, que afectan a importantes cultivos como papa y tomate (Rivas 1994; Polston y Anderson 1999).

La mosca blanca de los invernaderos se adapta bien a regiones con altitudes entre 800 y $3,000 \mathrm{msnm}$ (valles interandinos y zonas de ladera), con temperaturas promedio de $18{ }^{\circ} \mathrm{C}$ a $22^{\circ} \mathrm{C}$ y humedad relativa superior a $60 \%$; sin embargo, en la actualidad también se encuentra en poblaciones relativamente altas entre 0-200 msnm. Las lluvias fuertes son un factor importante en la dinámica de población de mosca blanca, porque disminuyen el número de adultos en campo y pueden desprender gran cantidad de ninfas, lo cual ocasiona disminución de los niveles de infestación (Rivas 1994; Polston y Anderson 1999).

La duración del estado adulto varía considerablemente de machos a hembras, siendo de 5 a 15 días para los primeros y de 5 a 32 para las hembras en las condiciones antes descritas. Algunos estudios indican que una hembra es capaz de depositar hasta 300 huevos durante su vida y que los huevos de hembras vírgenes producen machos, mientras que las que han copulado dan origen a los dos sexos. En condiciones tropicales, $T$. vaporariorum puede tener de 11 a 15 generaciones por año (Cardona et al. 2005).

La mosca blanca de los invernaderos es atacada por varios parasitoides como Encarsia spp. y Eretmocerus californicus Howard; depredadores como Chrysopa spp., y entomopatógenos como Beauveria bassiana (Balsamo) Vuillemin, Lecanicilium lecanii Zimm., y Paecilomyces fumosoroseus (Wize) (Cardona et al. 2005).

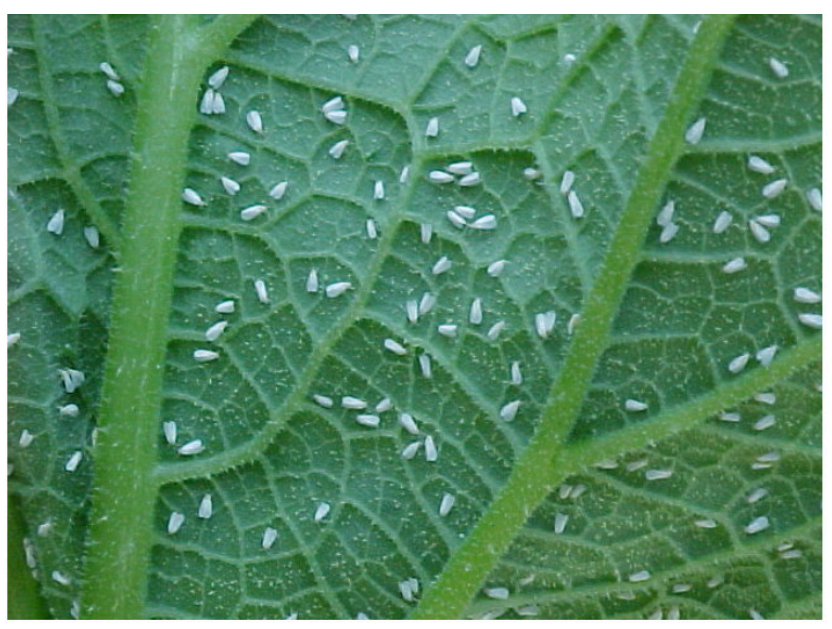

Figura 10. Adultos de Trialeurodes vaporariorum en envés de hoja de calabaza (L. Ortega). 
Aleurocanthus woglumi (Ashby, 1915)

La mosca prieta de los cítricos Aleurocanthus woglumi es nativa del sureste asiático y ocurre en Pakistán, India, Indonesia, Filipinas, Malasia y Sri Lanka. Se ha dispersado a lo largo de Asia y su distribución incluye a centro y sur de África, Centroamérica y algunas regiones del Norte y sur de América; no está presente en Europa y Región del Mediterráneo (CABI 2019).

En América, la mosca prieta fue citada por primera vez en Jamaica en 1913; de esta región se dispersó a Cuba y Bahamas en 1916, a Panamá en 1917, a Costa Rica en 1919 y a Cayo Hueso, Florida, EUA, en 1934 de donde fue erradicada (Newell y Brown 1939; Smith et al., 1964; CABI 2019). Actualmente se encuentra distribuida prácticamente en todo Centroamérica y algunas regiones del Norte y sur de América. En México, se citó por primera vez en la Hacienda de Redo, en el Dorado, Sinaloa, de donde se dispersó hacia el norte y sur por la costa occidental. Para 1943 la distribución ya incluía todo Sinaloa, Colima, Jalisco y Nayarit; en 1948 se encontraba presente en los estados de Aguascalientes, Baja California Sur, Guerrero, Michoacán, San Luis Potosí, Sonora, Veracruz y Zacatecas (Smith et al. 1964). Actualmente la mosca prieta de los cítricos se encuentra presente en los 23 estados citrícolas del país (SENASICA 2017; CABI 2019).

Los adultos de esta plaga son de color grisáceo oscuro $\mathrm{u}$ oscuros con rayas rojas en su tórax y abdomen, y miden de 0.99 a $1.24 \mathrm{~mm}$ de largo, aunque las hembras pueden alcanzar hasta $1.70 \mathrm{~mm}$; sus alas poseen manchas blancas. El apareamiento se lleva a cabo poco después de que emergen. Las hembras depositan sus huevos, color blanco mate y forma ovalada, en el envés de la hoja en grupos de 35 a 50 , los cuales son fácilmente reconocidos por su forma en espiral. Las hembras de la mosca prieta llegan a producir más de 100 huevos en su vida adulta, misma que es de casi 10 días. El ciclo de vida de esta plaga se completa de 2 a 4 meses dependiendo de las condiciones climáticas del lugar donde se desarrolla (Shaw 1950). Los factores que influyen más sobre la duración del ciclo son la humedad relativa y la distribución de la precipitación, ya que en los meses de mayor precipitación sus poblaciones se reducen drásticamente o desaparecen. Las condiciones adecuadas para su desarrollo son temperaturas de 28 a $32{ }^{\circ} \mathrm{C}$ y de 70 a $80 \%$ de humedad relativa. La mosca prieta de los cítricos no sobrevive a temperaturas menores a $0{ }^{\circ} \mathrm{C}$ o superiores a $43{ }^{\circ} \mathrm{C}$ (Nguyen et al. 2013) (Figura 11).

Al igual que otros aleiródidos, la mosca prieta de los cítricos daña a las plantas al succionar la savia bruta que sintetizan, misma que se segrega en grandes cantidades de mielecilla. Las hojas, ramas y frutos son cubiertos por esta capa dulce y pegajosa, que se puebla por un crecimiento micelial superficial de color negro que forma una película (fumagina), de manera que las partes atacadas de las plantas adquieren un aspecto sucio (Nguyen et al. 2013; SENASICA 2017). En México, el ataque de esta plaga puede reducir hasta en $80 \%$ la fructificación en cítricos e incluso en ataques severos causar la pérdida total de la producción por la caída de frutos y la defoliación ocasionada. Se reportan reducciones de más de $90 \%$ de la producción cuando las infestaciones exceden de 5 a 7 ninfas $/ \mathrm{cm}^{2} /$ hoja (SENASICA 2017) (Figura 11).

A. woglumi infesta más de 300 plantas hospederas, incluidas en 38 familias pero prefiere los cítricos en los cuales puede completar su ciclo de vida y ocasionar daños considerables (Shaw 1950; Smith et al. 1964; Sánchez-Soto et al. 2018). Esta especie ocurre comúnmente en una amplia diversidad de otros cultivos, sobre todo árboles frutales como bananos (Musa spp.), aguacate (Persea americana Mill.), café (Coffea arabica L.), jengibre (Zingiber officinale Rosc.), uva (Vitis vinifera L.), guayaba (Psidium guajava L.), lichi (Litchi chinensis Sonn.), mango (Mangifera indica L.), papaya (Carica papaya L.), pera (Pyrus spp.), granada (Punica granatum L.), membrillo (Cydonia oblonga Mill.) y rosa (Rosa spp.) (Smith et al. 1964; Sánchez-Soto et al. 2018).

En 1951 se inició en México un programa de control de esta plaga a escala nacional, el cual evolucionó en un eficiente y armonioso programa de control biológico que resultó en el control satisfactorio de la misma a partir de septiembre de 1962, en donde se utilizaron algunos parasi-

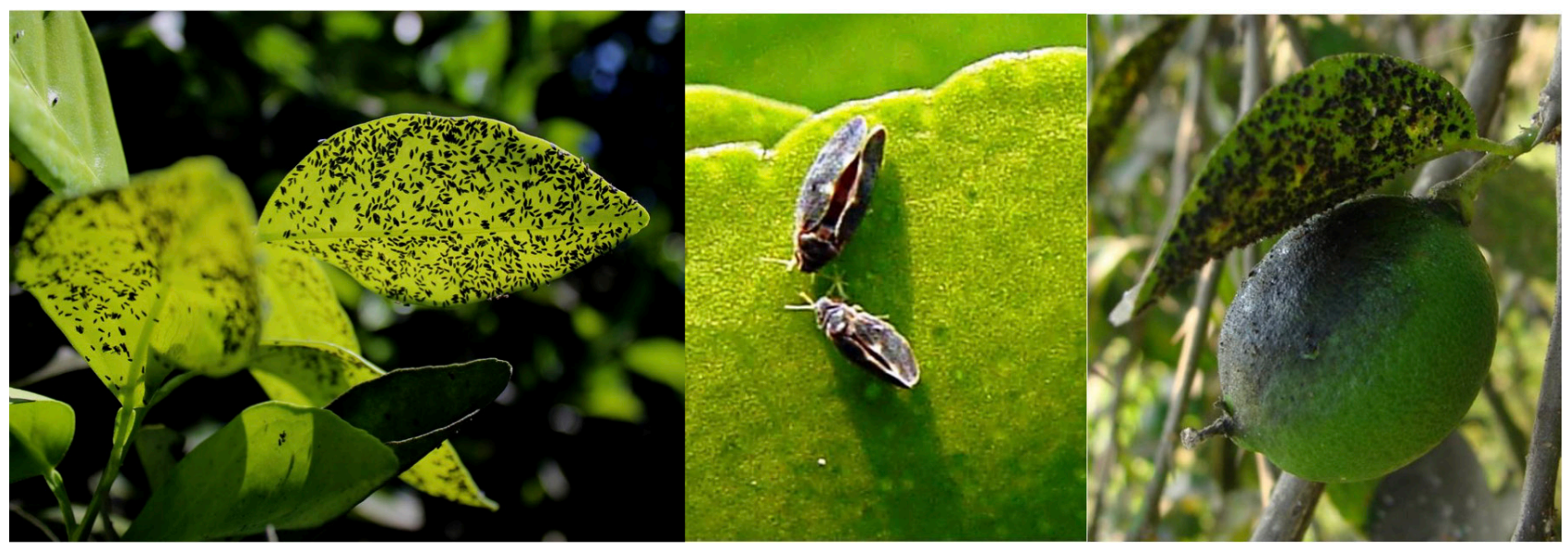

Figura 11. Adultos y daños asociados a la presencia de la mosca prieta de los cítricos Aleurocanthus woglumi (CESVO 2015). 
toides, incluyendo Encarsia perplexa Huang \& Polaszek, introducida con el nombre de Prospaltella opulenta Silvestri (Jiménez 1963; Smith et al. 1964). Sin embargo, y a pesar de que se implementaron programas de control biológico clásico, para controlar y eliminar nuevos brotes, a nivel nacional (Smith et al. 1964), en la actualidad se siguen presentando infestaciones fuertes y recientes en estados productores de cítricos como Oaxaca, Colima, Morelos, y Tamaulipas, debido en gran parte al uso inapropiado de insecticidas dirigidos al combate del complejo HLB-Diaphorina, pulgones y ácaros, mismos que eliminaron la fauna benéfica (CESVO 2015; SENASICA 2017).

\section{LITERATURA CITADA}

Anderson, P.K. 2000. La mosca blanca vectora: Bemisia tabaci (Genn.). In: F. J. Morales (Ed.). El Mosaico dorado y otras enfermedades del frijol común causadas por geminivirus transmitidos por mosca blanca en la América Latina (pp. 107-127). Centro Internacional de Agricultura Tropical (CIAT), Palmira, Colombia.

Baker, J.M. 1937. Notes on some Mexican Aleyrodidae. Anales del Instituto de Biología de la Universidad Nacional Autónoma de México, (8): 599-629.

Bayhan, E., M.R. Ulusoy, and J.K Brown. 2006. Host range, distribution, and natural enemies of Bemisia tabaci, B

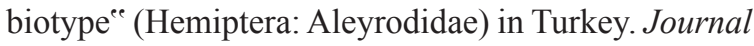
of Pest Science, 79(4): 233-240.

Bellows, T.S., T. M. Perring, R.J. Gill and D.H. Headrick. 1994. Description of a new species of Bemisia (Homoptera: Aleyrodidae). Annals of the Entomological Society of America, 87(2): 195-206.

Bethke, J. A., T. D. Paine and G.S. Nuessly. 1991. Comparative biology, morphometrics and development of two populations of Bemisia tabaci (Homoptera: Aleyrodidae) on cotton and poinsettia. Annals of the Entomological Society of America, 84(4): 407-411.

Bink-Moenen, R.M. and L.A. Mound. 1990. Whiteflies: diversity, biosystematics and evolutionary patterns. (pp. 1-11). In: Gerling D. (Ed.). Whiteflies: their biology and management. Intercept Ltd., Andover, UK.

Boykin, L.M., Ch.D. Bell, G. Evans, I. Small and P.J. De Barro. 2013. Is agriculture driving the diversification of the Bemisia tabaci species complex (Hemiptera: Sternorrhyncha: Aleyrodidae)? Dating, diversification and biogeographic evidence revealed. BMC Evolutionary Biology, 13: 228. http://www.biomedcentral.com/14712148/13/228.

Brown, J.K., and J. Bird. 1992. Whitefly-transmitted geminivirus in the Americas and the Caribbean Basin: past and present. Plant Disease, 76(3): 220-225.

Brown, J.K., D. Frohlich and R. Rosell. 1995. The sweetpotato/silverleaf whiteflies: biotypes of Bemisia tabaci (Genn.), or a species complex? Annual Review of Entomology, 40(1): 511-534.

Butler, G.D. 1982. Development of sweetpotato whitefly and temperature. Imperial Agricultural Briefs. USA 4 p. (mimeografiado)

Byrne, D.N. and T. S. Bellows. 1991. Whitefly biology. Annual Review of Entomology, 36(1): 431-457.

Byrne, D.N., T.S. Bellows and M.P. Parrella. 1990. Whiteflies in agricultural systems (pp: 227-261). In: Gerling D. (Ed.). Whiteflies: Their bionomics, pest status and management. Intercept Ltd., Andover Hants.

CABI. 2019. Invasive Species Compendium. Aleurocanthus woglumi (citrus blackfly) https://www.cabi.org/ isc/datasheet/4137. Fecha de consulta 19 abril de 2019.

Campbell, B.C., J.D. Steffen-Campbell and R.J. Gill. 1995. Origin and radiation of whiteflies: an initial molecular phylogenetic assessment (pp. 29-51). In: Gerling D. and R.T. Mayer (Eds.). Bemisia 1995: Taxonomy, biology, damage control and management. Andover, Hants: Intercept Ltd.

Carapia-Ruiz, V. E. and O. A. Sánchez-Flores. 2018. Moscas blancas (Hemiptera: Aleyrodidae) de México. Entomología Mexicana, 5: 616-621.

Carapia-Ruíz, V.E. and O.A. Sánchez-Flores, O. García-Martínez y A. Castillo-Gutiérrez. 2018a. Estudio morfológico de Aleuropleurocelus abnormis (Quaintance) (Hemiptera: Aleyrodidae) y nuevos registros de especies del género para México. Acta Zoológica Mexicana (n.s.) 34(1): 1-5.

Carapia-Ruíz, V.E. and O.A. Sánchez-Flores, O. García-Martínez y A. Castillo-Gutiérrez. 2018b. Descripción de dos especies nuevas del género Aleuropleurocelus Drews y Sampson, 1956 (Hemiptera: Aleyrodidae) de México. Insecta Mundi, (0606): 1-13.

Carapia-Ruíz, V.E. and O.A. Sánchez-Flores, O. García-Martínez y A. Castillo-Gutiérrez.2018c. Descripción de dos especies del Género Aleuropleurocelus de México. Southwestern Entomologist, 43(2): 517-526.

Carapia-Ruiz, V.E., O.A. Sánchez-Flores, I.E. Pochotitla-Campos y A. Castillo-Gutiérrez. 2016. Estudio del género Tetraleurodes Cockerell (Hemiptera: Aleyrodidae) de México. Entomología Mexicana, 3: 836-84.

Carapia-Ruíz, V.E., O.A. Sánchez-Flores, I.E. Lima-Sánchez, O. García-Martínez and A. Castillo-Gutiérrez. 2017. Whiteflies of the tribe Trialeurodini (Hemiptera: Aleyrodidae) its host plants and distribution in Mexico. Entomología Mexicana, 4: 837-840.

Carapia-Ruiz, V.E., H. González-Hernández, J. Romero-Nápoles, L.D. Ortega-Arenas y S.D. Koch. 2003. Descripción de dos nuevas especies de Trialeurodes (Cockerell) (Homoptera: Aleyrodidae) y una clave para las especies de México. Acta Zoológica Mexicana, (90): 93-101.

Carapia-Ruiz V.E., A. Macías-Flores, y A. Castillo-Gutiérrez. 2013. Género Paraleyrodes (Hemiptera: Aleyrodidae) de Nayarit, México. Investigación Agropecuaria, 10 (1): 49-58.

Carapia-Ruíz, V.E., E. Franco-Cortes y A. Castillo-Gutiérrez. 2016. Moscas blancas de la Subfamilia Aleuro- 
dicinae Quaintance y Baker (Hemiptera: Aleyrodidae) y clave para especies de México. Entomología Mexicana, 3: 859-863.

Carapia-Ruiz, V.E., A. Castillo-Gutiérrez, M.E. Núñez-Valdez, G. Peña-Chora, V.M. Hernández-Velásquez e Y. Ortega-Saad. 2009a. Género Bemisia (Hemiptera: Aleyrodidae) y clave para especies de México. Entomología Mexicana, 8: 993-998.

Carapia-Ruíz, V.E., A. Castillo-Gutiérrez, Y. Ortega-Saad, V.M. Hernández-Velásquez, G. Peña-Chora and M.E. Nuñez-Valdez. 2009b. Description of Cuautlaleyrodes canisgen. et sp. nov. of whiteflies (Hemiptera: Aleyrodidae) from Mexico. Tecno INTELECTO, 6 (1): 2-7.

Carapia-Ruiz, V.E., O.A. Sánchez-Flores, A. Castillo-Gutiérrez. 2017. Descripción de una especie nueva del género Tetraleurodes Cockerell (Hemiptera: Aleyrodidae) de México. Acta Zoológica Mexicana (n.s.), 33(2): 243-250.

Carapia-Ruiz V.E. y O.Á. Sánchez-Flores. 2019. Descripción de la primera especie pálida del género Aleuropleurocelus. Southwestern Entomologist, 44(1): 315319.

Carapia-Ruiz V.E. y A. Castillo-Gutiérrez. 2011. Estudios del género Paraleyrodes (Hemiptera: Aleyrodidae) y clave para México. Investigación Agropecuaria, 8(1): $62-\quad 68$.

Carapia, R., V.E. 2006. Descripción de dos especies nuevas de Trialeurodes de la Península de Yucatán México. Acta Zoológica Mexicana (n. s.), 22(1): 36- 42.

Carapia, R., V.E. 2007. Description of new species and new records of genus Trialeurodes Cockerell (Homoptera: Aleyrodidae) from México. Folia Entomológica Mexicana, 46(2): 79-84.

Cardona, C., I.V. Rodríguez, J. M. Bueno y X. Tapia. 2005. Biología y manejo de la mosca blanca Trialeurodes vaporariorum en habichuela y fríjol. Colombia: Centro Internacional de Agricultura Tropical. http://ciat-library.ciat.cgiar.org/ Articulos_Ciat/Car\%C3\%Altula.pdf. Fecha de consulta: 19 febrero de 2005.

Chu, D., F.H. Wan, Y.J. Zhang and J.K. Brown. 2010. Change in the biotype composition of Bemisia tabaci in Shandong Province of China from 2005 to 2008. Environmental Entomology, 39(3): 1028-1036.

Cockerell, T.D. 1898.Three new Aleyrodidae from Mexico. Psyche, 8: 225-226.

Cockerell, T.D. 1902. A synopsis of the Aleyrodidae of Mexico. Memories Revista Sociedad Cientifica "Antonio Alzate" México, 18(II): 203-208.

Comité Estatal de Sanidad Vegetal de Oaxaca (CESVO). 2015. Campaña Mosca Prieta de los Cítricos. 4 p. http://www.cesvo.org.mx/moscaprieta/index.html. Fecha de consulta: 9 de mayo de 2015.

Corbett, G.H. 1935. Malayan Aleurodidae. Journal of the Federated Malay States Museums, 17: 722-852.

De Barro P. J., Liu S. S., Boykin L. M., Dinsdale A. B. 2011. Bemisia tabaci: A statement of species status.
Annual Review of Entomology, 56(1): 1-19.

DGSV- SAGAR. 1995. Reporte México. In: Memorias del IV Taller Latinoamericano sobre moscas blancas y geminivirus. CEIBA, 36(1): 29-32.

Evans, G.A. 2007. The whiteflies (Hemiptera: Aleyrodidae) of the world and their host plants and natural enemies. USDA/Animal Plant Health Inspection Service (APHIS) http://keys. lucidcentral.org/keys/v3/whitefly/PDF_PwP\%20ETC/world-whitefly-catalog-Evans.pdf. Fecha de consulta: 10 octubre de 2018.

Evans, G.A. 2008. The whiteflies (Hemiptera: Aleyrodidae) of the world and their host plants and natural enemies. http://www.sel.barc.usda.gov/whitefl y/wfframe.htm. Fecha de consulta: 18 abril de 2019).

Gennadius, P. 1889. Disease of tobacco plantations in the trikonia. The aleurodid of tobacco. Ellenike Georgia (Grecia), 5(1): 1-3.

Gerling, D. 2002. Una reinterpretación sobre las moscas blancas. Manejo Integrado de Plagas (Costa Rica), (63): 13-21.

Gill, R.J. 1990. The morphology of whiteflies (pp. 13-46). In: Gerling D. (Ed.). Whiteflies: their bionomics, pest status and management. Intercept Ltd., Andover Hants.

Horowitz, A.R., Y. Antignus and D. Gerling. 2011. Management of Bemisia tabaci whiteflies (pp: 293-322). In: Thompson W.M.O. (Ed.). The whitefly, Bemisia tabaci (Homoptera: Aleyrodidae) interaction with geminivirus-infected host plants. Springer Dordrecht, https:// www.researchgate.net/publication/225986300_Management_of_Bemisia_tabaci_Whiteflies. Fecha de consulta: 10 de abril de 2019.

Isaacs, R. and D.N. Byrne. 1998. Aerial distribution, flight behavior and eggload: their inter-relationship during dispersal by the sweetpotato whitefly. Journal of Animal Ecology, 67(5): 741-750.

Jiménez, E., 1963. Control biológico de la mosca prieta en México. Fitofilo México 16(37): 5-41.

Johnson, M.W., N.C. Toscano, H.T. Reynolds, E.S. Sylvester, K.R. Kido and E.T. Natwick, 1982. Whiteflies cause problems for Southern California growers. California Agriculture, 36(1): 24-26.

Kirkaldy, G.W. 1907. A catalogue of the hemipterous family Aleyrodidae. Bulletin. Bd. Commissioners of Agriculture Hawaii Division Entomology, (2): 1-92.

Lee, W., J. Park, G. Lee, S. Lee, S. Akimoto. 2013. Taxonomic status of the Bemisia tabaci complex (Hemiptera: Aleyrodidae) and reassessment of the number of its constituent species. PLoS One 8 (5): e6381710.1371/journal.pone.0063817.

León, R. 1993. Mosquita blanca: Daños e impacto en la agricultura regional (pp. 23-25). In: Memorias de la Primera Reunión Regional sobre problemas fitosanitarios del Noroeste de México. IAP. A.C.

León, R., M. Cervantes y J.B. Sánchez. 1996. Monitoreo Regional de mosca blanca en algodonero y toma de 
decisiones. DDR 002, Río Colorado 1996 (pp. 25-31). In: Memorias II reunión binacional sobre control de la mosquita blanca y otras plagas del algodonero. Publicación especial No. 5. Mexicali B. C. México.

Liu, S., J. Colvin, P. De Barro. 2012. Species concepts as applied to the whitefly Bemisia tabaci systematics: how many species are there? Journal of Integrative Agriculture, 11(2): 176-186.

McAuslane, H.J., J. Cheng, R.B. Carle, and J. Schmalstig. 2004. Influence of Bemisia argentifolii (Homoptera: Aleyrodidae) infestation and squash silverleaf disorder on zucchini seedling growth. Journal of Economical Entomology, 97(3): 1096-1105.

Martin, J.H., S. Hernández, E. Suárez and A. Carnero. 1997. An introduced new species of Lecanoideus (Homoptera: Aleyrodidae) established and causing economic impact on the Canary Islands. Journal of Natural History, 31(8): 1261- 1272.

Martin, J.H. 1987. An identification guide to common whitefly pest species of the world (Homoptera: Aleyrodidae). Tropical Pest Management, 33(4): 298-322.

Martin, J.H. 1999. The whitefly fauna of Australia (Stemorrhyncha: Aleyrodidae). A taxonomy account and identification guide. Technical Paper $N^{\circ} 38$, CSRO, Canberra Australia.

Martin, J.H. and L.A. Mound. 2007. An annotated check list of the world's whiteflies (Insecta: Hemiptera: Aleyrodidae. Zootaxa, (1492): 1-84.

Martin, J.H. 2008. A revision of Aleurodicus Douglas (Sternorrhyncha: Aleyrodidae) with two new genera proposed for paleotropical natives and an identification guide to world genera of Aleurodicinae. Zootaxa, (1935): 1-100.

Martin, J.H. 2007. Giant whiteflies (Sternorrhyncha, Aleyrodidae): a discussion of their taxonomic and evolutionary significance, with the description of a new species of Udamoselis Enderlein from Ecuador. Tijdschrift voor Entomologie, 150: 13-29.

Martin, J.H. and J.M. Camus. 2001. Whiteflies (Sternorrhyncha, Aleyrodidae) colonizing ferns (Pteridophyta: Filicopsida), with descriptions of two new Trialeurodes and one new Metabemisia species from south-east Asia. Zootaxa, (2): 1-19.

Martin, J.H., D. Mifsud and C. Rapisarda. 2000. The whiteflies (Hemiptera: Aleyrodidae) of Europe and Mediterranean Basin. Bulletin of Entomological Research, 90(5): 407-448.

Martínez C., J.L. 1995. Problemática fitosanitaria causada por la mosquita blanca en México. pp. 76-88. In: Memorias de la segunda asamblea anual del CONACOFI 1994. Montecillo, Edo. de México.

Martínez C., J.L. and J.K. Brown. 2007. First report of the Q biotype of Bemisia tabaci (Gennadius) in southern Sonora, Mexico. Phytoparasitica, 35(3): 282-284. https://doi.org/ 10.1007/BF02981162.
Mound, L.A. 1984. Zoogeographical distribution of whiteflies. Current Topics in Vector Research, 23: 185-197.

Mound, L.A. and S.H. Halsey. 1978. Whitefly of the World. A systematic catalog of the Aleyrodidae (Homoptera) with host plant and natural enemy data. British Museum (Natural History)/John Wiley \& Sons, Chichester.

Mound, L.A., J.H. Martin and A. Polaszek. 1994. The insect fauna of Selaginella (Pteridophyta: Lycopsida), with descriptions of three new species. Journal of Natural History, 28(6): 1403-1415.

Naranjo, S.E. and P.C. Ellsworth. 2009. The contribution of conservation biological control to integrated pest control of Bemisia tabaci in cotton. Biological Control, 51(3): 458-470.

Nava-Camberos, U., D.G. Riley and M. Harris. 2001. Temperature and plant effects on development, survival, and fecundity of Bemisia argentifolii (Homoptera: Aleyrodidae). Environmental Entomology, 30(1): 5563.

Newell, W. and A.C. Brown. 1939. Eradication of the citrus blackfly in Key West, Fla. Journal of Economic Entomology, 32: 680-682.

Nguyen R., A. B. Hamon and T. R. Fasulo. 2013. Citrus blackfly, Aleurocanthus woglumi Ashby (Insecta: Hemiptera: Aleyrodidae). University of Florida, UF/IFAS Extension, Gainesville, FL. EENY-042 4 p. https:// edis.ifas.ufl.edu/pdffiles/IN/IN19900.pdf

Oliveira, M.R.V., T.J. Henneberry, P. Anderson. 2001. History, current status, and collaborative research projects for Bemisia tabaci. Crop Protection, 20: 709-723.

Ortega A., L.D. 1995. Colecta, Montaje y determinación de Aleyrodidae. Fitofilo, 88 (XLVIII): 53-70.

Ortega A., L.D. 2008. Bioecología de moscas blancas (pp. 1-6). In: S. Infante G. (Ed.). Moscas Blancas: Temas selectos sobre su manejo. Colegio de Postgraduados. Mundi Prensa, Mexico, D.F.

Ouvrard, D. and J.H. Martin. 2019. The White-flies: Taxonomic checklist of the world's whiteflies (Insecta: Hemiptera: Aleyrodidae). http://www.hemiptera-databases.org/ whiteflies/ Searched. Fecha de consulta: 14 de marzo de 2019.

Pan, H., D. Chu, W. Yan, Q. Su, B.S. Liu, Q. Wang, W. Wu, X. Xie, R. Jiao, N. Li, X. Yang, B. Yang, J. Xu, J.K. Brown, X. Zhou and Y. Zhang. 2012. Rapid spread of tomato yellow leaf curl virus in china is aided differentially by two invasive whiteflies. PLOS ONE, 7(4): e34817. doi:10.1371/journal.pone.0034817.

Perring, T.M. 2001. The Bemisia tabaci species complex. Crop Protection, 20(9): 725-737.

Perring, T.M., A.D. Cooper, R.J. Rodríguez, R.J. Farrar and C.A. Bellows. 1993. Identification of whitefly species by genomic and behavioral studies. Science, 259(5091): 74-77.

Polston, J.E. y P.K. Anderson. 1999. Surgimiento y distribución de geminivirus transmitidos por mosca blanca 
en tomate en el hemisferio occidental. Manejo Integrado de Plagas (Costa Rica), (53): 24- 42.

Quaintance, A.L. 1900. Contribution towards a monograph of the American Aleurodidae. Technical Services Bureau of Entomology U. S., 8: 9-64.

Quaintance, A.L. 1908. Homoptera, Family Aleyrodidae. Genera Insectorum, 87: 1-11.

Quaintance, A.L. and A.C. Baker. 1913. Classification of the Aleyrodidae Part I. Technical Series, United States Department of Agriculture Bureau of Entomology, 27: $1-93$.

Quaintance, A.L. and A.C. Baker. 1914. Classification of the Aleyrodidae Part II. Technical Series, United States Department of Agriculture Bureau of Entomology, 27: 95-109.

Quaintance, A.L. and A.C. Baker. 1937. Notes on some Mexican Aleyrodidae. Anales del Instituto de Biología, Universidad Nacional Autónoma de México, S 8: 599-629.

Rapisarda, C. 1985. Trialeurodes (Ericaleyrodes) Sardini$a e$, subgen. n., sp.n.: A new heather feeding whitefly (Homoptera: Aleyrodidae). Frustula Entomologica, 7-8: 487-499.

Rivas, P., G.G. 1994. Geminivirus: Virus transmitidos por las moscas blancas. Hoja Técnica Boletín Informativo $M I P N^{\circ} 33$. Costa Rica.

Romay, G., F. Geraud-Pouey, D. Chirinos and J. Demey. 2016. Bemisia tabaci (Gennadius) (Hemiptera: Aleyrodidae): History, current status and its role as plant vector of viral diseases in Venezuela. Entomotropica, 31(35): 276-293.

Russell, L.M. 1943. A new genus and four new species of whiteflies from the West Indies (Homoptera: Aleyrodidae). Proceedings of the Entomological Society of Washington, 45: 131-141.

Russell, L.M. 1948. The North American species of whiteflies of the genus Trialeurodes. Miscellaneous publications. United States Department of Agriculture, 635: 1-85.

Russell, L.M. 1957. Synonyms of Bemisia tabaci (Gennadius) (Homoptera: Aleyrodidae). Bulletin of the Brooklyn Entomological Society, 52: 122-123.

Salvucci, M.E., G.R. Wolfe and D.L. Hendrix. 1997. Effect of sucrose concentration on carbohydrate metabolism in Bemisia argentifolii: Biochemical mechanism and physiological role for trehalulosa synthesis in the silverleaf whitefly. Journal of Insect Physiology, 43(5): 457-464.

Sampson, W.W. and E.A. Drews. 1941. Fauna Mexicana IV. A review of the Aleyrodidae of México. Anales de la Escuela Nacional de Ciencias Biológicas, 2: 143189.

Sánchez-Flores O. A., V.E. Carapia-Ruíz., O. García-Martínez, A. Castillo-Gutiérrez., J.F. García-Ochaeta. 2017a. Descripción de cuatro especies nuevas de Aleurovitreus Martin (Hemiptera: Aleyrodidae) y cla- ve para especies del Género. Insecta Mundi, 0655: $1-15$.

Sánchez-Flores, O.A., O. García-Martínez y V.E. Carapia-Ruiz. 2017b. Primer registro para México de Aleuroparadoxus arctostaphyli Russell, 1947 (Hemiptera: Aleyrodidae), sus hospederos, distribución y parasitoide. Acta Zoológica Mexicana (n.s.), 33(1): 143-145.

Sánchez-Flores, O.A. and V.E. Carapia-Ruiz. 2018a. Nueva especie de Aleuropleurocelus Drews y Sampson (Hemiptera: Aleyrodidae) y clave para especies del grupo de forma oval. Insecta Mundi, (0651): 1-12.

Sánchez-Flores, O. A., V.E. Carapia-Ruiz. 2018b. Description of two new species of the genus Aleuropleurocelus Drews \& Sampson (Hemiptera: Aleyrodidae) from Mexico. Acta Zoológica Mexicana (nueva serie), 34(2): 1-9.

Sánchez-Flores, O.A., V.E. Carapia-Ruíz, O. García-Martínez, A. Castillo-Gutiérrez. 2018a. Primer registro para México de Aleurothrixus myrtacei Bondar, 1923 (Hemiptera: Aleyrodidae), sus hospederos y distribución. Acta Zoológica Mexicana (n.s.), 34(1): 1-3.

Sánchez-Flores, O.A., V.E. Carapia-Ruíz., O. García-Martínez, A. Castillo-Gutiérrez. 2018b. Descripción de una especie nueva del género Aleuropleurocelus Drews y Sampson (Hemiptera: Aleyrodidae) de México. Acta Zoológica Mexicana (n.s.), 34(2): 1-6.

Sánchez-Flores, O.A., V.E. Carapia-Ruíz., O. García-Martínez, A. Castillo-Gutiérrez. 2018c. Descripción de una especie nueva del Género Aleuropleurocelus de México. Southwestern Entomologist, 43(1): 257-262.

Sánchez-Flores, O.A., V.E. Carapia-Ruíz., O. García-Martínez, J.A. Villarreal-Quintanilla, A. Castillo-Gutiérrez. 2017. Descripción de una nueva especie del género Tetraleurodes Cockerell (Hemiptera: Aleyrodidae) y clave para las especies de México. Insecta Mundi, 0583: 1-11.

Sánchez-Soto, S., D. Sumano-López, G. Pascual-Córdova, A. Córdova-Sánchez, V. González-Jiménez, A. Ramírez-García. 2018. Reporte de Aleurocanthus woglumi Ashby Hemiptera: Aleyrodidae) dañando cítricos (Citrus spp.) en la Depresión Central de Chiapas, México. Revista Nicaragüense de Entomología, (156): 1- 9.

Shaw, J.G. 1950. Hosts of the citrus blackfly in Mexico. United States Bureau of Entomology and Plant Quarantine, E-793, 3 pp.

Secker, A.E., I.D. Bedford, P.G. Markham and M.E. de Courcy-Williams. 1998. Squash, a reliable field indicator for the presence of the B biotype tobacco whitefly, Bemisia tabaci. British Crop Protection Council, Brighton Conference, 3: 837-842.

SENASICA. 2017. Estrategia de la campaña contra mosca prieta de los cítricos en 2017. https://www.gob.mx/ cms/uploads/attachment/file/176184/Estrategia MPC_2017.pdf 
Shah, M.M. and T.X. Liu. 2013. Feeding experience of Bemisia tabaci (Hemiptera: Aleyrodidae) affects their performance on different host plants. PLOS ONE 8, e77368.

Shahab M. and D. Quicke J. 2006. A cladistic analysis of whiteflies, subfamily Aleyrodinae (Hemiptera: Sternorrhyncha: Aleyrodidae), Journal of Natural History, 40(44-46): 2423-2554.

Smith, H.D., H.L. Maltby and E. Jiménez-Jiménez. 1964. Biological control of the citrus blackfly in Mexico. Technical Bulletin No. 1311. U.S. Department of Agriculture. Washington, D.C.

Takahashi, R. 1951. Some species of Aleyrodidae (Homoptera) from Madagascar with a species of Mauritius. Memoirs of the Scientific Institute of Madagascar, 6: 353-385.

Teng Xi, W. Fang-Hao and D. Chu. 2010. "Bemisia tabaci Biotype Q dominates other biotypes across China. Florida Entomologist, 93(3): 363-368.

Thompson, W.M.O. 2003. A new host plant species for the cassava biotype of Bemisia tabaci (Gennadius) (Hom., Aleyrodidae). Journal of Applied Entomology, 127(6): 374-376.

van Lenteren J.C. and L.P. Noldus. 1990. Whitefly plant relationships: behavioral and ecological aspects (pp: 47-89). In: Gerling D. (Ed.). Whiteflies: their bionomics, pest status and management. Intercept Ltd., Andover Hants.

Xu, J., P.J. De Barro and S.S. Liu. 2010. Reproductive incompatibility among genetic groups of Bemisia tabaci supports the proposition that the whitefly is a cryptic species complex. Bulletin Entomological Research, 100 (3): 359-366.

$\mathrm{Xu}$, J., K.K. Lin, and S.S. Liu. 2011. Performance on different host plants of an alien and an indigenous Bemisia tabaci from China. Journal of Applied Entomology, 135(10): 771-779.

Recibido: 25 de septiembre 2019

Aceptado: 3 de diciembre 2019
Cuadro 2. Especies de Aleyrodidae citadas en México (Carapia-Ruiz y Sánchez-Flores 2018).

Aleurodicinae Quaintance \& Baker, 1913

Aleurodicus araujoi Sampson y Drews, 1941

Aleurodicus coccolobae Quaintance y Baker, 1913

Aleurodicus cocois Curtis, 1846

Aleurodicus dugesii Cockerell, 1896

Aleurodicus etiennei Martin, 2008

Aleurodicus maritimus Hempel, 1922

Aleurodicus mirabilis (Cockerell), 1898

Aleurodicus niveus Martin, 2004

Aleurodicus pulvinatus (Maskell), 1896

Aleurodicus rugioperculatus Martin, 2004

Aleuronudus acapulcensis Sampson y Drews, 1941

Aleuronudus mani Baker, 1923

Diaeurodicus radifera (Sampson y Drews), 1941

Diaeurodicus silvestri (Leonardi), 1910

Paraleyrodes ancora Martin, 2004

Paraleyrodes citriculus Costa Lima, 1928

Paraleyrodes minei Iaccarino, 1990

Paraleyrodes perseae (Quaintance), 1900

Paraleyrodes proximus Terán, 1979

Paraleyrodes pseudonaranjae Martin, 2001

Nealeurodicus altissimus (Quaintance, 1900)

\section{Aleyrodinae Westwood, 1840}

Aleurocanthus woglumi Ashby, 1915

Aleurocerus ceriferus (Sampson y Drews), 1941

Aleurocerus chiclensis Russell, 1986

Aleurocerus palmae Russell, 1986

Aleurocybotus occiduus Russell, 1964

Aleuroglandulus striatus Sampson y Drews, 1941

Aleuroglandulus subtilis Bondar, 1923

Aleuroparadoxus arctostaphyli Russell, 1947

Aleuroparadoxus gardeniae Russell, 1947

Aleuroparadoxus iridescens (Bemis), 1904

Aleuroparadoxus rhodae Russell, 1947

Aleuroparadoxus silicicola Russell, 1947

Aleuroparadoxus truncates Russell, 1947

Aleuroplatus berbericolus Quaintance y Baker, 1917

Aleuroplatus cococolus Quaintance y Baker, 1917

Aleuroplatus coronate (Quaintance), 1900

Aleuroplatus dentatus Sampson y Drew, 1941

Aleuroplatus ovatus Quaintance y Baker, 1917

Aleuroplatus vinsonioides (Cockerell, 1898)

Aleuropleurocelus abnormis (Quaintance, 1900)

Aleuropleurocelus acaudatus Drews y Sampson, 1958

Aleuropleurocelus anahuac Carapia y Sánchez, 2018

Aleuropleurocelus anonae Carapia y Sánchez, 2018

Aleuropleurocelus bidentatus Sánchez y Carapia, 2018

Aleuropleurocelus caudatus Sánchez y Carapia, 2018

Aleuropleurocelus ceanothi (Sampson), 1945

Aleuropleurocelus chamaedoreaelegans Sánchez y

Carapia, 2018

Aleuropleurocelus guerrerensis Carapia y Sánchez, 2018 
Aleuropleurocelus hyptisemoryi Gill, 2011

Aleuropleurocelus mexicanus Carapia y Sánchez, 2018

Aleuropleurocelus nevadensis Dooley, 2010

Aleuropleurocelus nigrans (Bemis), 1904

Aleuropleurocelus xalapensis Sánchez y Carapia, 2018

Aleurothrixus chivelensis (Sampson y Drews), 1941

Aleurothrixus floccosus (Maskell), 1895

Aleurothrixus myrtacei Bondar, 1923

Aleurothrixus trachoides (Back), 1912

Aleurothrixus romeronapolesi Carapia, 2019

Aleurotithius mexicanus Russell, 1947

Aleurotrachelus atratus Hempel, 1922

Aleurotrachelus tracheifer (Quaintance), 1900

Aleurotulus sp.*

Aleurovitreus mariae Sánchez y García, 2018

Aleurovitreus piperschiedeanum Sánchez y Carapia, 2018

Aleurovitreus pueblensis Sánchez y Carapia, 2018

Aleurovitreus tuberculatus Sánchez y Carapia, 2018

Aleurovitreus risor Martin, 2005

Asiothrixus similis (Sampson y Drews), 1941

Bemisia afer (Priesner y Hosny), 1934

Bemisia caudasculptura Quaintance y Baker 1937

Bemisia centroamericana Martin, 2005

Bemisia tabaci (Gennadius, 1889)

Cuautlaleyrodes canis Carapia, 2009

Dialeurodes citri (Ashmead, 1885)

Dialeurodes denticulatus (Bondar), 1923

Dialeurodes egregissima (Sampson y Drews), 1941

Dialeurodes kirkaldyi (Kotinsk), 1907

Hesperaleyrodes michoacanensis Sampson, 1943

Minutaleyrodes minuta (Singh), 1931

Parabemisia myricae (Kuwana), 1927

Paraleurolobus chamaedoreae Russell, 1994

Paraleurolobus imbricatus Sampson y Drews, 1941

Pealius sp.*

Singhiella citrifolii (Morgan), 1898

Singhiella simplex (Singh), 1931

Siphoninus phillyreae (Haliday), 1835

Tetraleurodes acacia (Quaintance), 1900

Tetraleurodes bidentatus Sampson y Drews, 1941

Tetraleurodes bireflexa Nakahara, 1995

Tetraleurodes caulicola Nakahara, 1995

Tetraleurodes chivela Nakahara, 1995
Tetraleurodes contigua (Sampson y Drews), 1941

Tetraleurodes dorsibandas Sánchez y Carapia, 2017

Tetraleurodes fici Quaintance y Baker, 1937

Tetraleurodes melanops (Cockerell), 1903

Tetraleurodes mexicana Nakahara, 1995

Tetraleurodes mori (Quaintance), 1899

Tetraleurodes perileuca (Cockerell), 1902

Tetraleurodes perseae Nakahara, 1995

Tetraleurodes pringlei Quaintance y Baker, 1937

Tetraleurodes quadrates Sampson y Drews, 1941

Tetraleurodes quercicola Nakahara, 1995

Tetraleurodes tepalcingo Carapia, 2017

Tetraleurodes truncates Sampson y Drews, 1941

Tetraleurodes ursorum Cockerell, 1910

Trialeurodes abutiloneus (Haldeman), 1850

Trialeurodes amealcensis Carapia-Ruiz, 2003

Trialeurodes bellissima (Sampson y Drews), 1940

Trialeurodes bemisae Russell, 1948

Trialeurodes campecheanensis Carapia, 2004

Trialeurodes coccolobae Russell, 1948

Trialeurodes corollis (Penny), 1922

Trialeurodes criptus Martin, 2005

Trialeurodes floridensis (Quaintance, 1900)

Trialeurodes glacialis (Bemis), 1904

Trialeurodes intermedia Russell, 1948

Trialeurodes ipomoeae Carapia-Ruiz, 2003

Trialeurodes mirissimus Sampson y Drews, 1941

Trialeurodes multipori Russell, 1948

Trialeurodes oblongifoliae Russell, 1948

Trialeurodes oswaldoi Carapia 2006

Trialeurodes quitanarroensis Carapia, 2004

Trialeurodes similis Russell, 1948

Trialeurodes tentaculatus (Bemis), 1904

Trialeurodes tephrosiae Russell, 1948

Trialeurodes vaporariorum (Westwood), 1856

Trialeurodes varia Quaintance y Baker, 1937

Trialeurodes variabilis (Quaintance), 1900

Trialeurodes vitrinellus (Cockerell), 1903 